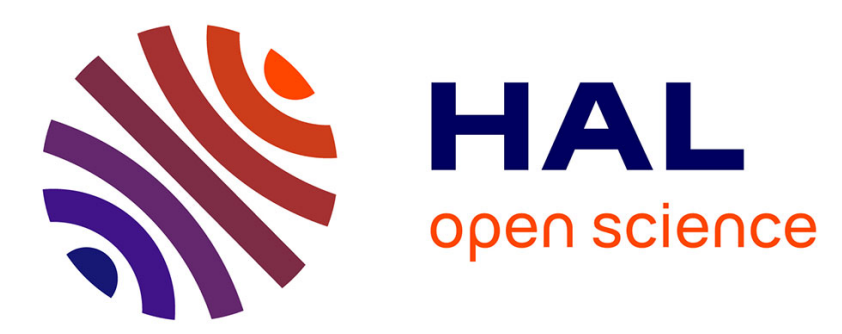

\title{
The Potential of a Multidecade Spaceborne Lidar Record to Constrain Cloud Feedback
}

Hélène Chepfer, Vincent Noël, Marjolaine Chiriaco, B. Wielicki, D. Winker, N. Loeb, R. Wood

\section{- To cite this version:}

Hélène Chepfer, Vincent Noël, Marjolaine Chiriaco, B. Wielicki, D. Winker, et al.. The Potential of a Multidecade Spaceborne Lidar Record to Constrain Cloud Feedback. Journal of Geophysical Research: Atmospheres, 2018, 123 (10), pp.5433-5454. 10.1002/2017JD027742 . insu-01779101

\section{HAL Id: insu-01779101 https://hal-insu.archives-ouvertes.fr/insu-01779101}

Submitted on 8 Sep 2020

HAL is a multi-disciplinary open access archive for the deposit and dissemination of scientific research documents, whether they are published or not. The documents may come from teaching and research institutions in France or abroad, or from public or private research centers.
L'archive ouverte pluridisciplinaire HAL, est destinée au dépôt et à la diffusion de documents scientifiques de niveau recherche, publiés ou non, émanant des établissements d'enseignement et de recherche français ou étrangers, des laboratoires publics ou privés. 


\section{Journal of Geophysical Research: Atmospheres}

\author{
RESEARCH ARTICLE \\ 10.1002/2017JD027742 \\ Key Points: \\ - Space born lidar record could \\ constrain cloud feedback \\ - Intercalibration shift between \\ successive lidar missions would delay \\ the capability to constrain cloud \\ feedback \\ - Signatures of longwave cloud tropical \\ cloud feedback might be observed \\ first
}

Supporting Information:

- Supporting Information S1

Correspondence to:

H. Chepfer,

chepfer@lmd.polytechnique.fr

\section{Citation:}

Chepfer, H., Noel, V., Chiriaco, M., Wielicki, B., Winker, D., Loeb, N., \& Wood, R. (2018). The potential of a multidecade spaceborne lidar record to constrain cloud feedback. Journal of Geophysical Research: Atmospheres, 123, 5433-5454. https://doi.org/10.1002/2017JD027742

Received 15 SEP 2017

Accepted 21 MAR 2018

Accepted article online 18 APR 2018

Published online 23 MAY 2018

C2018. American Geophysical Union. All Rights Reserved.

\section{The Potential of a Multidecade Spaceborne Lidar Record to Constrain Cloud Feedback}

\author{
H. Chepfer ${ }^{1}$ (D) V. Noel ${ }^{2}$, M. Chiriaco ${ }^{3}$, B. Wielicki ${ }^{4}$, D. Winker ${ }^{4}$, N. Loeb ${ }^{4}$, and R. Wood ${ }^{5}$ \\ ${ }^{1}$ LMD/IPSL, Sorbonne Université, UPMC Université Paris 06, École polytechnique, Université Paris Saclay, ENS, PSL Research \\ University, CNRS, Paris, France, ${ }^{2}$ Laboratoire d'Aérologie, CNRS, Toulouse, France, ${ }^{3}$ LATMOS/IPSL, Université Versailles Saint \\ Quentin en Yvelines, Guyancourt, France, ${ }^{4}$ NASA LaRC, Hampton, VA, USA, ${ }^{5}$ Department of Atmospheric Sciences, \\ University of Washington, Seattle, WA, USA
}

Abstract Synthetic multidecadal spaceborne lidar records are used to examine when a cloud response to anthropogenic forcing would be detectable from spaceborne lidar observations. The synthetic records are generated using long-term cloud changes predicted by two Coupled Model Intercomparison Program 5 models seen through the COSP/lidar (CFMIP, Cloud Feedback Model Intercomparison Project, Observation Simulators Package) and cloud interannual variability observed by the CALIPSO (Cloud Aerosol Lidar and Infrared Pathfinder Satellite Observations) spaceborne lidar during the past decade. CALIPSO observations do not show any significant trend yet. Our analysis of the synthetic time series suggests that the tropical cloud longwave feedback and the Southern Ocean cloud shortwave feedback might be constrained with $70 \%$ confidence with, respectively, a 20-year and 29-year uninterrupted lidar-in-space record. A 27-year record might be needed to separate the two different model predictions in the tropical subsidence clouds. Assuming that combining the CALIPSO and Earth-CARE (Earth Clouds, Aerosols and Radiation Explorer) missions will lead to a spaceborne lidar record of at least 16 years, we examine the impact of gaps and calibration offsets between successive missions. A 2-year gap between Earth-CARE and the following spaceborne lidar would have no significant impact on the capability to constrain the cloud feedback if all the space lidars were perfectly intercalibrated. Any intercalibration shift between successive lidar missions would delay the capability to constrain the cloud feedback mechanisms, larger shifts leading to longer delays.

Plain Language Summary The atmospheric water cycle has many components (clouds, aerosol, precipitation, and water vapor), and how they interact with the other climate elements to produce the precipitation necessary for life on land is complex. How this cycle will evolve over the coming decades in a warming world is uncertain and must be more fully understood. There are currently unprecedented opportunities to increase our understanding and capacity to predict cloud changes. Pioneering satellite missions developed over the last decade have provided for the first time observed detailed profiles of clouds on a global scale. Such profiles are especially important because they are expected to change faster and with larger amplitudes in response to human-caused climate modifications than the other characteristics of clouds. Here we show that multidecade global-scale climate record of cloud profiles obtained by combining observations collected by successive space lidars (pulsed lasers) could likely be used to identify fingerprints of human-caused cloud modifications.

\section{Introduction}

Multimodel analysis suggests that cloud response to anthropogenic forcing will contribute to enhance the Earth warming. While the global multimodel annual mean longwave (LW) and shortwave (SW) cloud feedback are positive based on CFMIP (Cloud Feedback Model Intercomparison Project) simulations (Zelinka et al., 2012), these predictions are not yet fully verified in the observations and the multimodel spread remains significant. As a consequence, clouds remain the main source of uncertainty for model-based estimates of climate sensitivity and for future climate prediction (e.g., Boucher et al., 2013; Ceppi et al., 2017; Colman, 2003; Soden \& Held, 2006; Ringer et al., 2006; Webb et al., 2006; Vial et al., 2013). Constraining cloud feedback is a necessary step for progressing in our confidence in future climate predictions.

As passive visible/infrared satellites have been observing clouds at global scale for a few decades (e.g., Loeb et al., 2013; Norris \& Slingo, 2009; Stubenrauch et al., 2013), they are a priori good candidates to provide observational constraints on cloud feedback mechanisms at play in the current climate. Nevertheless, cloud observations have 
not been useful for constraining cloud feedback mechanisms so far, because they are limited to documenting only a few variables of the system, usually with insufficient accuracy, and at insufficient spatial and time scales. Moreover, the available records ( 25 years at most) are likely too short to unravel the natural variability of the climate system from the response to anthropogenic forcing. Finally, as the stability in time of the measurements is often inadequate in comparison to the expected amplitude of the signal tracked, the accuracy of the retrievals is also an issue. Acknowledging these limits, recent studies (Marchand et al., 2010; Marvel et al., 2015; Norris et al., 2016) explored advanced analysis of satellite observations to detect cloud change and cloud feedback signatures due to climate warming in current passive sensor satellite records, and Wielicki et al. (2013) explored the potential of long-term almost perfect top of the atmosphere (TOA) spectral radiance measurements.

As the vertical distribution of clouds is more sensitive to climate forced changes than vertical integrated variables (Chepfer et al., 2014), long-term observations from spaceborne active sensors (lidar/radar) might be indispensable tools to constrain cloud feedback. Cloud observations from active sensors are likely more accurate and likely more stable in time than those from passive remote sensing satellites (Winker et al., 2017), and active sensors provide direct measurements of the detailed vertical distribution of clouds and precipitations, key variables for climate. But today, the active sensor records are limited to the 12 years observed by CALIPSO lidar (Winker et al., 2010) and CloudSat radar (Stephens et al., 2002). This does not allow yet to constrain cloud feedback mechanisms. The four-year Earth-CARE lidar/radar satellite mission (Illingworth et al., 2015) will be launched in 2020 to complement the existing record, but Earth-CARE instruments have significantly different characteristics compared to CALIPSO/Cloudsat (Reverdy et al., 2015), and the Earth-CARE overpass local time is $30 \mathrm{~min}$ later than CALIPSO. The purpose of this paper is to explore the potential of a multidecades active satellite sensors record-here a lidar-to constrain cloud feedback mechanisms and to constrain cloud feedback spread predicted by climate models.

Using climate model simulations and physical understanding of the physics of the climate system, Klein and Hall (2015) identified cloud feedback mechanisms that are playing in both the current climate and a warmer climate and that are likely also driving the cloud response to climate warming. For example, they highlighted the sensitivity of the extratropical low-level cloud optical depth to temperature and the sensitivity of the subtropical marine low-level cloud cover to sea surface temperature (SST). Learning from this study, we examined simulated current climate atmospheres and simulated warmer climate atmospheres through a lidar lens (thanks to a lidar simulator). We defined three different cloud diagnostics observable with a space lidar that should contain the signature of cloud feedback mechanisms in three regions: the "low cloud volume" in subsidence tropical region, the "opaque cloud altitude" in deep convective tropical region, and the opaque "cloud volume" in the Southern Ocean. We built synthetic, hundred-years lidar record of these cloud diagnostics, their long-term trend being forced by climate model simulations, and their intradecadal variability being forced by CALIPSO observations (Diagram 1). Using this hundred-year record, we explored the capability of a long-term spaceborne lidar time series to constrain the tropical deep convective LW feedback, the SW subsidence tropical feedback, and the extratropical cloud SW feedback. In particular, we examine how long the lidar record would need to be (1) for the forced cloud change to be detectable, that is for the forced cloud change to get out of the natural climate variability; (2) to constrain the sign of the feedback in each region; and (3) to constrain the magnitude of the feedback in each region, assuming that the climate models were correct. Then, adapting a method proposed by Loeb, Wielicki, Doelling, et al. (2009), we perturb the hundred years record, assuming calibration errors or gaps between successive active sensor space missions within the record, in order to estimate their impacts on the capability to constrain cloud feedback.

Section 2 presents the observations and modeling tools. Section 3 presents the motivation for the selection of feedback, regions, and cloud diagnostics. Section 4 describes the method used to estimate when a forced cloud change would be detectable. Section 5 shows the results in the three regions (tropical ascent, tropical descent, and Southern Ocean) and examines the impact of mission gaps and intercalibration shifts between successive lidar missions.

\section{Tools}

\subsection{Observations}

To describe the cloud radiation at the TOA, we used Clouds and the Earth's Radiant Energy System (CERES)-Energy Balanced and Filled Edition 2.8 (Loeb, Wielicki, Doelling, et al., 2009; Loeb et al., 2012) 

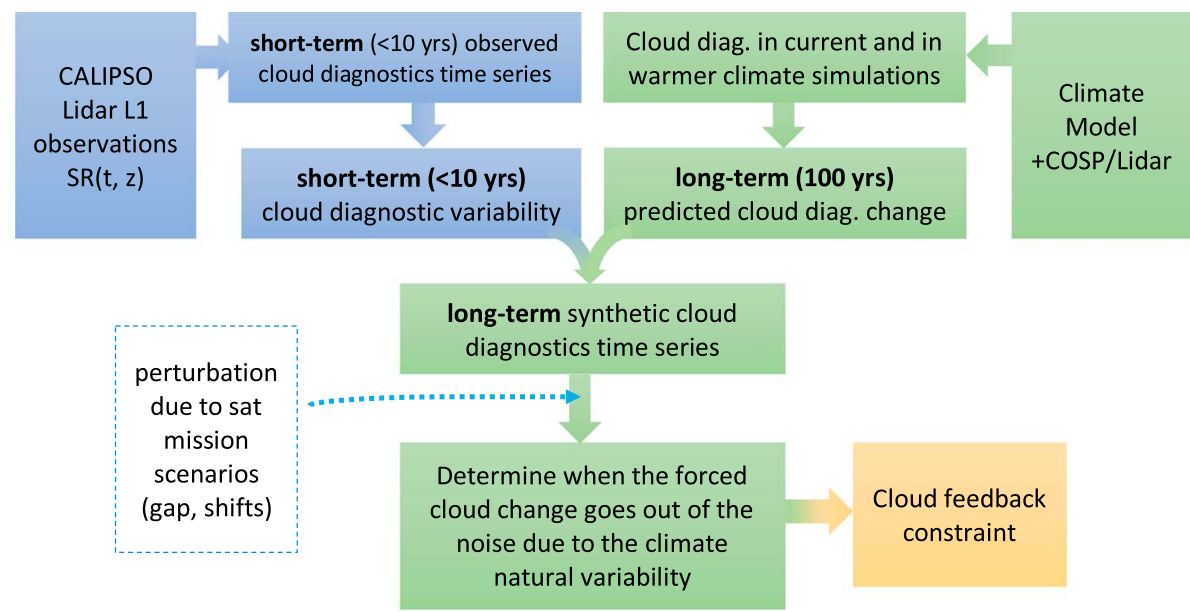

Diagram 1. Observation and model data processing chain. Lidar observation processing is in blue and illustrated in Figure 1. Processing of model output is in green. Cloud feedback constraints are in orange.

upward TOA SW and TOA LW fluxes as a well as the cloud radiative effect (CRE) in the SW and LW derived from CERES observations during the CALIPSO time period.

To characterize the cloud amount and the cloud vertical distribution, we used observations collected by spaceborne lidar that do not face the same calibration challenges as passive visible/infrared instruments do. Lidar data are calibrated by comparisons between the profile of observed stratospheric molecular backscatter with the modeled values derived from radiosonde or numerical weather prediction model forecasts of temperature and pressure (Chepfer et al., 2010). This can be done more accurately than passive sensor calibration, which involves using onboard calibration sources that can degrade with time. Our analysis uses nine years of CALIPSO-General Circulation Model (GCM) Oriented Cloud Climate Product (CALIPSO-GOCCP, fully described in Chepfer et al., 2010, 2013) collected during the last decade.

1. Single profiles. We use the profile of scattering ratio (SR), defined as the ratio of the Attenuated Backscatter Lidar profile (ATB) measured by Cloud-Aerosol Lidar with Orthogonal Polarization (CALIOP) to the Attenuated molecular Backscatter Lidar profile (ATBmol) that would be observed if the atmosphere consisted of only molecules-no aerosols and no clouds. Each vertical profile is made of 480-m-thick layers from the surface to the tropopause and documents an atmospheric column of $330 \mathrm{~m}$ (along the satellite track) by $75 \mathrm{~m}$ (cross track).

2. Gridded height-intensity histograms. The height intensity histograms are fully described in Chepfer et al. (2010). They inherit from the CloudSat radar Cloud Frequency Altitude Diagnostic (Marchand et al., 2010) and have been widely used for evaluating the cloud description in climate models (e.g., BodasSalcedo et al., 2011; Chakroun et al., 2016; Nam \& Quaas, 2012).

Height-intensity histograms are built for each $2^{\circ} \times 2^{\circ}$ grid box by accumulating all the SR profiles within that grid box during a month. The histograms of the various grid boxes included in a given region can be summed up. The histograms of different months can also be summed up. As an example, Figure 1a shows the heightintensity histogram for Tropical convective regions over the last decade: it is the sum of the monthly heightintensity histograms from the $2 \times 2^{\circ}$ grid boxes located between latitudes $\pm 30^{\circ}$ where and when the monthly averaged vertical wind speeds at $500 \mathrm{hPa}$ is ascending (w500 <0).

The height-intensity histogram lets one visually identify the cloud types. Intensity values ( $x$ axis in Figure 1a) close to 1 correspond to clear-sky layers, and layers with small values of intensities $(1.2<\mathrm{SR}<5)$ correspond typically to aerosol layers. Figure 1a shows many high-altitude echoes (10-17 km) of intermediate intensity ( $5<\mathrm{SR}<30$ ), typical of cirrus of moderate optical depth (3 to 5). At lower altitude, below $2 \mathrm{~km}$, some lowaltitude large-intensity echoes ( $\mathrm{SR} \sim 80$ below $2 \mathrm{~km}$ ) are typical of boundary layer cumulus. Below $10 \mathrm{~km}$, Figure 1a shows numerous extremely weak intensities $(S R<0.01)$ in the leftmost column corresponding to opaque clouds with optical depth larger than 5; these clouds fully attenuated the laser. 
a) SR histogram, Tropical deep convection

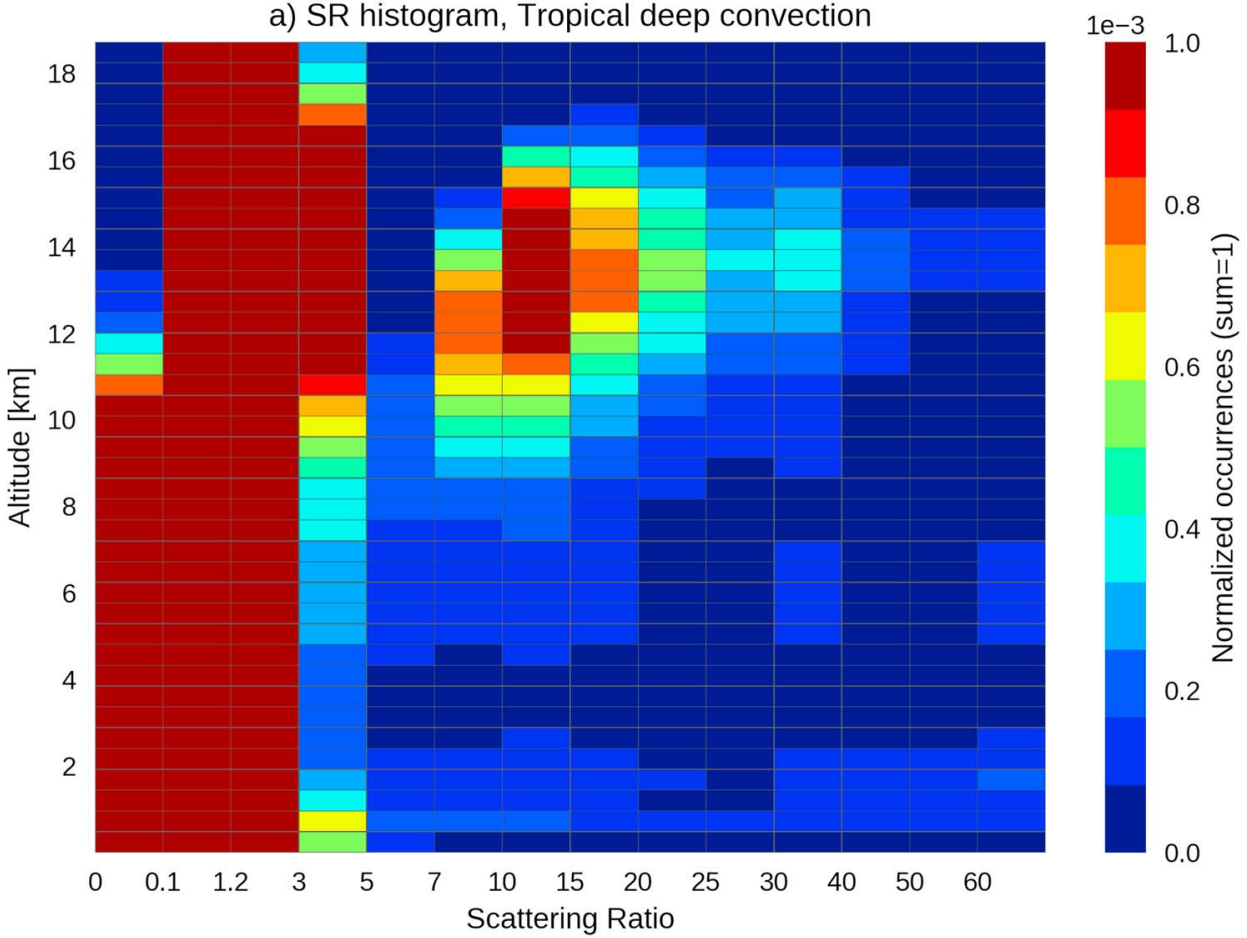

b) Opaque clouds diagnostics

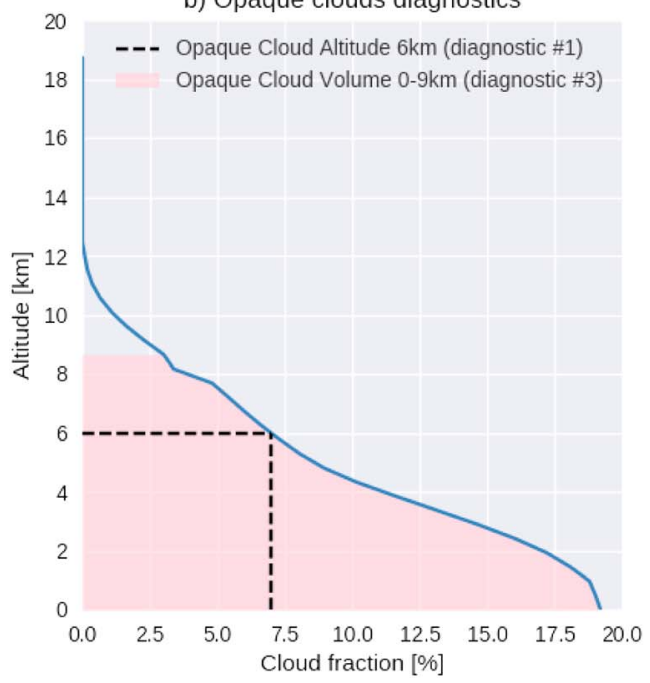

c) Thin clouds diagnostics

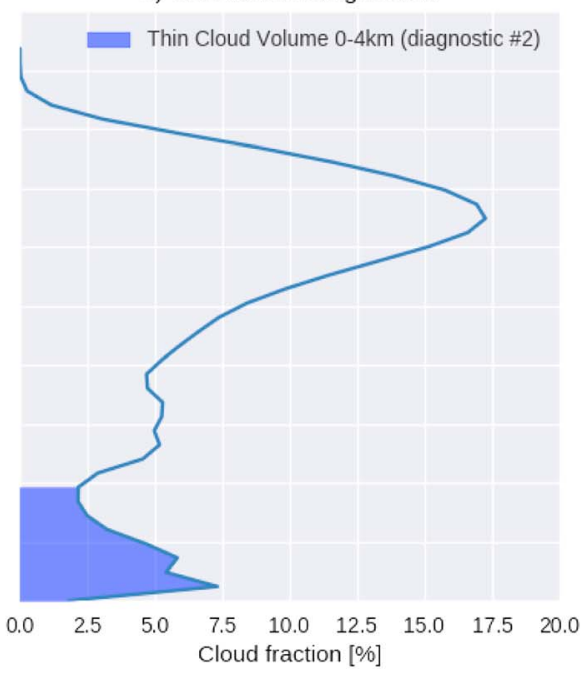

Figure 1. Construction of the cloud diagnostics in tropical deep convection region. (a) Height-SR intensity histogram for tropical deep convection region. (b) Opaque cloud fraction profile (blue line) opaque cloud volume (pink shade), and opaque cloud fraction at $6 \mathrm{~km}$ of altitude (black dashed lines) built from (a). (c) Thin cloud profile (blue line) and low cloud volume (blue shade) built from (a). Figure 1a sums up gridded monthly histograms from CALIPSO-GOCCP collected between $30^{\circ} \mathrm{N}$ and $30^{\circ} \mathrm{S}$ during the period $2008-2014$ over grid boxes where monthly vertical air speed is ascending at $500 \mathrm{hPa}$ based on ERA-Interim reanalysis. CALIPSO observations collected before the laser tilt (2006-2007) are not used.

We used height-intensity histograms to build vertical profiles of opaque cloud fraction (CF; Figure 1b) and vertical profiles of optically thin CF (Figure 1c) as in Chepfer et al. (2014). The thin CF profile is the number of occurrence in thin cloud bins $(5<\mathrm{SR}<80$ ) divided by the total number of occurrence (all SR bins) at a given level. The opaque CF profile is the number of occurrence in opaque cloud bins $(S R<0.01)$ divided by the total number of occurrence (all SR bins) at a given level. In Figure 1c, the thin CF reaches a maximum of $17.5 \%$ in the upper troposphere and the opaque CF a maximum of $19 \%$ in the lower 
troposphere. Values of thin/opaque CF are always much smaller than values of cloud cover: a grid box containing 10 single profiles will have a cloud cover of $100 \%$ if each of the 10 single profiles contains at least one cloudy layer ( $480 \mathrm{~m}$ thick), while this same grid box will have a CF profile of $10 \%$ if each of the 10 single profiles contains a single cloudy layer ( $480 \mathrm{~m}$ thick) at a different altitude of the other single profiles.

From these optically thin and opaque CF profiles (Figures $1 \mathrm{~b}$ and $1 \mathrm{c}$ ) we build three cloud diagnostics:

The opaque cloud altitude (in kilometer) is the altitude at which the opaque CF in a given profile equals the opaque CF at $6 \mathrm{~km}$ in the current climate (black dotted horizontal line in Figure 1b). We choose $6 \mathrm{~km}$ because it is above the boundary layer and it is below $8 \mathrm{~km}$ where the CALIPSO lidar signal-to-noise ratio changes due to onboard satellite data averaging. A change in the opaque cloud altitude is due to a change in the altitude where the cloud emissivity is close to 1 in the thermal infrared (Vaillant de Guélis, Chepfer, Noel, Guzman, Dubuisson, et al., 2017). The opaque cloud altitude is strongly correlated to the TOA LW CRE (Guzman et al., 2017; Vaillant de Guélis, Chepfer, Noel, Guzman, Dubuisson, et al., 2017; Vaillant de Guélis, Chepfer, Noel, Guzman, Winker, et al., 2017). We use this diagnostic to study the LW feedback in the deep convective clouds in section 3.1.

The low cloud volume (in \%) is the sum of the vertically integrated opaque (Figure 1b) and thin (Figure 1c) CF profiles between the sea level and $4 \mathrm{~km}$. The low cloud volume is typically $11 \%$ in the tropical subsidence regions (Table S1). A change in the low cloud volume is due to a change in the boundary layer cloud horizontal extent (like a cloud cover change) and/or a change in the boundary layer cloud vertical extent. A change in the vertical extent can be associated to a change in optical thickness and a change in cloud optical depth when the cloud shrinks or grows up. Hence, the low cloud volume influences the outgoing SW flux at the TOA in the subsidence tropics. We use the low cloud volume to study the Cloud SW feedback in the tropical subsidence regions in section 3.2.

- The opaque cloud volume (in \%) is the vertically integrated opaque CF profile between the sea level and $9 \mathrm{~km}$ (filled pink area in Figure 1b). The opaque cloud volume is typically 10\% (Figure 1b) in the tropical convection region and $3 \%$ in the Southern Ocean (Table S1). It is less in the Southern Ocean than in the tropics, since Opaque clouds are mostly in the lower troposphere in the Southern Ocean, unlike in the tropics where they reach $9 \mathrm{~km}$ of altitude. In the Southern Ocean the opaque cloud volume is $3 \%$ while the cloud cover is larger than 70\%. This is due to two reasons: (1) most of the free troposphere does not contain opaque clouds (they are mostly in the lower troposphere) and (2) the CF profiles are always smaller than the cover. A change in the opaque cloud volume is due to a change in the cloud horizontal extent (like a cloud cover change) and/or a change in the vertical extent possibly associated to a change in optical thickness (like a cloud optical depth change). As a consequence, the opaque cloud volume influences the TOA outgoing SW flux (Guzman et al., 2017). We use the opaque cloud volume to study the cloud SW feedback in the Southern Ocean in section 3.3 .

\subsection{Climate Model Simulations and Lidar Simulator}

We built the same three cloud diagnostics-opaque cloud altitude, opaque cloud volume, and low cloud volume-as in the observations but using climate model simulations.

We considered global atmospheric properties generated by the Hadley Centre Global Environmental Model version 2-A (HadGEM2-A; Martin et al., 2011) and the Canadian Atmospheric Global Climate Model version 4 (CanAM4; von Salzen et al., 2013) GCMs. During the Coupled Model Intercomparison Program 5 (CMIP5; Taylor et al., 2012) and CFMIP-2 (Bony et al., 2009) projects, HadGEM2-A and CanAM4 outputs were processed through the CALIOP lidar simulator (Chiriaco et al., 2006; Chepfer et al., 2007, 2008) included in the CFMIP Observations Simulator Package (COSP, Bodas-Salcedo et al., 2011). The created synthetic lidar observations simulate what the CALIOP spaceborne lidar would observe if it was overflying the atmosphere predicted by HadGEM2-A and CanAM4. Those synthetic observations have been compared many times against actual ones to evaluate the description of clouds in climate models (e.g., Bodas-Salcedo et al., 2014; Cesana \& Chepfer, 2012, 2013; Kay et al., 2016; Klein et al., 2013; Nam \& Quaas, 2012). In the current paper we do not focus on the reliability of model cloud representation, but instead on how the models predict clouds will change in a future climate (Chepfer et al., 2014), and how these changes would appear if sampled by multidecades lidar observations. 
Here we used synthetic monthly height-intensity histograms generated from HadGEM2-A and CanAM4 outputs in 2008 conditions (the codenamed "AMIP" scenario, Atmospheric Model Intercomparison Program) and in a scenario where the global mean surface temperature increases by $+4 \mathrm{~K}$ in average (the AMIP $+4 \mathrm{~K}$ scenario). Only the AMIP and AMIP+4K scenarios feature the height-intensity histograms from COSP/lidar outputs needed for the current study; more complete runs featuring a fully couple atmosphere-ocean do not. In the rest of the study we use only these two models for which the height-intensity histogram outputs are available in AMIP and AMIP+4K. We used these simulated histograms to build the three simulated cloud diagnostics-opaque cloud altitude, opaque cloud volume, and low cloud volume-following the same steps as for the observations in section 2.1.

\section{Selection of Feedback, Regions, and Cloud Diagnostics}

\subsection{Positive LW Feedback in the Deep Convective Clouds}

Our current understanding of the cloud feedback problem ties LW feedback to deep convective clouds (e.g., Soden \& Vecchi, 2011). While the LW cloud feedback is positive in global mean average among CMIP models $\left(+0.21 \mathrm{~W} \cdot \mathrm{m}^{-2} \cdot \mathrm{K}^{-1}\right)$, the magnitude of the predicted LW feedback varies significantly between models $\left(-0.13\right.$ to $\left.0.69 \mathrm{~W} \cdot \mathrm{m}^{-2} \cdot \mathrm{K}^{-1}\right)$. At global scale, HadGEM2-A $\left(0.20 \mathrm{~W} \cdot \mathrm{m}^{-2} \cdot \mathrm{K}^{-1}\right)$ is close to the CMIP multimodel mean value $\left(0.21 \mathrm{~W} \cdot \mathrm{m}^{-2} \cdot \mathrm{K}^{-1}\right)$, whereas CanAM4 $\left(0.62 \mathrm{~W} \cdot \mathrm{m}^{-2} \cdot \mathrm{K}^{-1}\right)$ is one of the models that predict the largest LW feedback.

Over the tropical deep convective region, CanAM4 remains larger $\left(0.57 \mathrm{~W} \cdot \mathrm{m}^{-2} \cdot \mathrm{K}^{-1}\right)$ than the multimodel mean over the same area $\left(0.39 \mathrm{~W} \cdot \mathrm{m}^{-2} \cdot \mathrm{K}^{-1}\right.$; Zelinka et al., 2012). Table S2 sums up the CREs for both models and scenarios.

\subsubsection{Choice of the Observable Cloud Diagnostic: Opaque Cloud Altitude}

The LW cloud feedback is tied dominantly to increase in cloud altitude. Increases in the height of tropical high clouds as the climate warms have been noticed in climate simulations for decades, going back at least as far as papers by Hansen et al. (1984) and Wetherald and Manabe (1988), and appearing in cloud-resolving models (Kuang \& Hartmann, 2007) and in GCMs. Hartmann and Larson (2002) explained this tendency as a consequence of the Fixed-Anvil Temperature (FAT) hypothesis. Zelinka and Hartmann (2010) ties the FAT and the Proportionately Higher Anvil Temperature (PHAT) hypotheses to LW CRE and LW cloud feedback. Because increases in cloud top height under climate warming are expected to exceed natural variability, cloud vertical distribution is a good candidate for a direct observable cloud response to anthropogenic forcing (Chepfer et al., 2014). For this reason we choose the opaque cloud altitude diagnostic to track the cloud change in the ascending tropical regions, that is defined as the region where the air is ascending at $500 \mathrm{hPa}$ (w500<0) between $\pm 30^{\circ}$ in latitude.

The restriction to negative w500 conditions in models and observations makes the forthcoming observation/model comparison less sensitive to differences in atmospheric large-scale circulations between model and observation (e.g., Bony et al., 2004): the model cloud diagnostics are used where the GCM w500 are negative, while the observed cloud diagnostics are used where reanalyses w500 are negative. We built observed time series of the cloud diagnostic as follow. We created decadal monthly height-intensity histograms (Figure $1 \mathrm{~b}$ ) by summing all the monthly height-histogram intensity contained in grid boxes where w500 $<0$ in the tropics ( $\pm 30^{\circ}$ latitude). We used ERA-Interim reanalyses (Dee et al., 2011 ) to derive appropriate maps of vertical wind speeds. We summed up all January height-intensity histograms from the last decade, and from the single histogram remaining (which spans the entire record) retrieved the value of opaque $\mathrm{CF}$ at $6 \mathrm{~km}$. We then retrieved for each month at which altitude the same value of opaque CF is reached. The obtained values create the diagnostic associated with opaque clouds in deep convection.

Figure 2a shows the time evolution of the anomaly in opaque cloud altitude over ascent tropics as observed by CALIPSO during the last decade: it remained stable and does not exhibit any significant trend.

\subsubsection{LW CRE Increases With the Opaque Cloud Altitude in the Observations and in the Models}

From Zelinka and Hartmann (2010, ZH2010 hereafter), LW CRE increases in a warmer climate, not because of the increase in the altitude of anvil clouds but because of an increase in high CF (see section 5.1 of ZH2010). The increase in anvil cloud altitude with a warming climate is, however, important for LW cloud feedback as explained in section 5.2 of $\mathrm{ZH} 2010$. An increase in the opaque cloud altitude diagnostic (section 2) can be due to either an increase in altitude of anvil clouds or an increase in the high CF profile. Discrimination between 

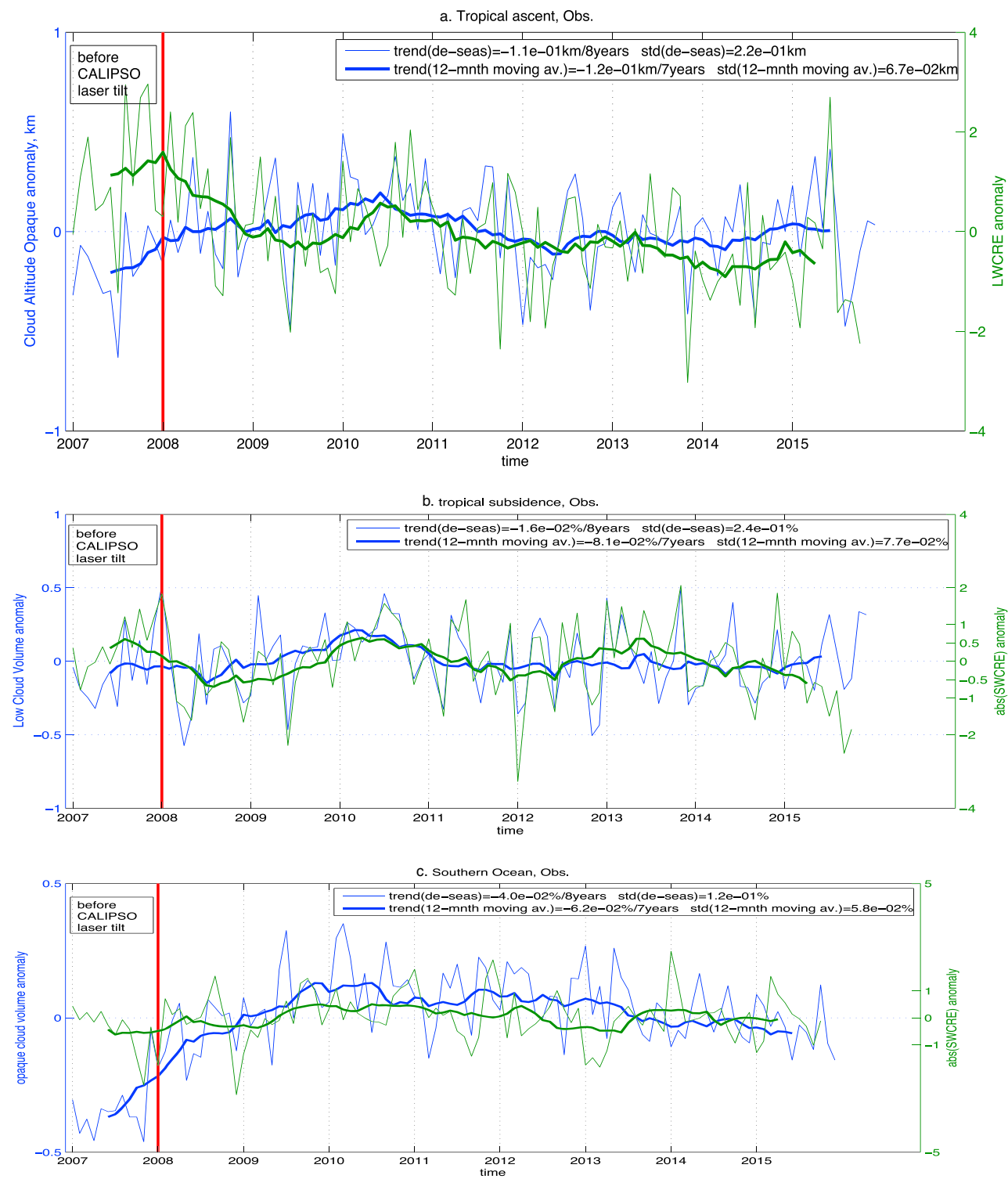

Figure 2. Observed time series of the cloud diagnostic anomaly in blue (CALIPSO) and the CRE anomaly green (CERES) over the last decade. (a) Ascent tropics. (b) Subsidence tropics. (c) Southern Ocean. The thin lines are the monthly anomalies (e.g., for (a) LWCRE January_2010-<LWCRE $>$ all_Januarys_2008_to_2015). The thick lines are the anomalies of the 12-month moving averaged (e.g., for (a) $<$ LWCRE $>$ 12_succesive_ months $-<$ LWCRE $>$ all_months_2008_to_2015). The red vertical line show the date at which the pointing of the CALIPSO-laser changed from $0.3^{\circ}$ to $3^{\circ}$ off nadir. The 12-month moving averaged (thick green and blue lines) are influenced by the laser pointing change until June 2008, and the monthly anomalies (thin green and blue lines) until January 2008. Only data collected $3^{\circ}$ off-nadir (after December 2007) are used to compute the values given in Table S1 and in the following figures.

the two effects might be possible in the actual lidar observations, but not in the COSP/lidar outputs that are currently available.

First, we examine if the opaque cloud altitude drives the CRE LW. The observations (Figure 2a) show that opaque cloud altitude anomaly is correlated with the CRE LW anomaly, except before 2008 when the CALIPSO laser pointed $0.3^{\circ}$ off-nadir and was frequently blinded by specular reflections from preferentially oriented ice crystals (e.g., Noel \& Chepfer, 2010). Values computed in Table S1 only use data collected after 2008, when CALIPSO was pointed $3^{\circ}$ off nadir. Comparing the variability of the opaque cloud altitude with the CRE LW in current climate (Table S1), we found that the CRE LW robustly increases with the opaque cloud altitude in 
both observations and models as expected, but the amplitude of the change differs: $+3.5 \mathrm{~W} / \mathrm{m}^{2}$ for a $+1 \mathrm{~km}$ elevation in the observations compared to +6.05 and $+1.96 \mathrm{~W} / \mathrm{m}^{2}$, respectively, in the two climate models. Independent single-column direct radiative transfer computation indicates that the CRE LW increases of $11 \%$ for an elevation of $+1 \mathrm{~km}$ for a typical optical thick clouds initially around $240 \mathrm{~K}$, which is consistent with the observations (8.3\%) and the HadGEM2-A rate (+14\%). The comparison between the observed increase and the model increase uses $\%$ instead of $\mathrm{W} / \mathrm{m}^{2}$ because the model absolute values are biased compared to the observations, as shown in Table S1 and in previous literature (Figure S03 in Chepfer et al., 2014) related to the evaluation of the model mean state. The correlation is smaller in the observations (0.7) than in the models (0.93) because the variation of the actual opaque cloud cover is larger than the simulated one. The significant correlations between the increase of the CRE LW and the opaque cloud elevation found within the observations, the numerical climate models, and the independent direct radiative transfer computation confirm that the opaque cloud altitude is a robust observable diagnostic that influences the CRE LW in deep convective tropical clouds.

\subsubsection{The Opaque Cloud Altitude Increases With the SST in the Observations and in the Models}

Here we examine how the opaque cloud altitude changes with SST in the current climate in the observations and in the models. In the observations (Figure 2a), the opaque cloud altitude increases over warm SST during an El Niño event like in 2010 and 2015 and decreases over low SST during a La Niña event like in 2008, 2011, and 2012, consistently with previous work (Su \& Jiang, 2013). Consistently with the observations, the HadGEM2-A opaque cloud altitude increases with SST but the model ( $+20 \% / \mathrm{K}$; Table S1) is much more sensitive to the SST than observations $(+4 \% / K)$. In the second model, CanAM4, the opaque cloud altitude does not vary with the SST in current climate, possibly because the SST range of variation is too small.

Finally, we examined the predicted change in the opaque cloud altitude in a warmer forced climate compared to current climate (Table S1). We consider the height-intensity histograms produced by the COSP lidar simulator applied on the atmospheric conditions simulated by HadGEM2-A and CanAM4 in the current climate (AMIP scenario; section 2). We sum these gridded histograms over the tropics $\left(30^{\circ} \mathrm{N}-30^{\circ} \mathrm{S}\right)$ in ascent conditions (monthly mean w500<0) as predicted by the GCM and derive the opaque CF at $6 \mathrm{~km}$ (as in Figure 1c, but from model + COSP outputs). We then follow the same procedure considering atmospheric conditions predicted by the GCMs in the warmer scenario (AMIP+4K). From the height-intensity histogram that eventually remains, we derive the opaque CF profile and find the altitude of clouds that create an opaque fraction equal to the one found at $6 \mathrm{~km}$ in current climate conditions. Considering the predicted atmosphere from the HadGEM2-A model in the tropical ascent region, this altitude is $7.44 \mathrm{~km}$ in $\mathrm{AMIP}+4 \mathrm{~K}$ conditions, a $+1.44 \mathrm{~km}$ altitude change compared to current climate (Table S1).

Both models consistently predict an elevation of the opaque cloud altitude for $\mathrm{a}+1 \mathrm{~K}$ increase of the global mean SST. Nevertheless, the ranges of these elevations differ from one model to another: $+6 \%$ and $+10 \%$, respectively, which is symptomatic of the intermodel spread of the LW cloud feedback described in Zelinka et al. (2012). Moreover, comparing HadGEM2-A changes in current climate conditions (+20\% for $+1 \mathrm{~K} \mathrm{SST}$ ) with HadGEM2-A changes in a warmer climate (+6\% for $+1 \mathrm{~K} \mathrm{SST}$, AMIP+4K) suggests that the LW feedback in current climate cannot be used as a direct qualitative proxy of the forced change as they vary by a factor of more than 3 .

\subsection{Cloud SW Feedback in the Tropical Subsidence Regions}

In the tropical subsidence region, multimodel simulations suggest that the response of clouds to greenhouse warming is uncertain: even the sign of the low-level tropical cloud feedback differs from one model to another. In this region, model simulations indicate that the cloud feedback is dominated by the SW term, whereas the LW term is small (Zelinka et al., 2012). In global mean, the sign and the magnitude of the cloud SW feedback vary a lot among models, typically from -0.2 to $+1 \mathrm{~W} \cdot \mathrm{m}^{-2} \cdot \mathrm{K}^{-1}$, whereas the two models used in the current study share small values $\left(0.09\right.$ and $0.41 \mathrm{~W} \cdot \mathrm{m}^{-2} \cdot \mathrm{K}^{-1}$; Table S2). For both models, the SW feedback in the subsidence tropical regions $\left(0.33\right.$ and $\left.0.42 \mathrm{~W} \cdot \mathrm{m}^{-2} \cdot \mathrm{K}^{-1}\right)$ is larger than the SW global means $\left(0.09\right.$ and $\left.0.41 \mathrm{~W} \cdot \mathrm{m}^{-2} \cdot \mathrm{K}^{-1}\right)$. This underlines the important contribution of this region to the total SW cloud feedback term. 
Recent model-based studies confirm the expectation for a positive cloud SW feedback mechanism (Qu et al., 2014, 2015; Klein \& Hall, 2015; Bretherton, 2015) in the subsidence tropical clouds: the cloud cover is expected to decrease as climate warms, while the cloud optical depth change and altitude change are expected to have negligible impact.

\subsubsection{Choice of the Observable Cloud Diagnostic: The Low Cloud Volume}

The subsidence tropical regions are dominated by two types of clouds, both confined in the boundary layer: (i) a large belt of shallow cumulus sparse clouds, which contain a significant amount of optically thin clouds (Konsta et al., 2012; Leahy et al., 2012), and (ii) optically thicker stratocumulus clouds located along the east coast of the oceans (e.g., Guzman et al., 2017) with frequent cumulus underneath the stratocumulus. These two populations are not independent, as the cloud optical depth varies from thin (typically $\tau<5$ ) to opaque (typically $\tau>5$ ).

Former studies (e.g., Klein \& Hall, 2015; Qu et al., 2014) suggested that low-level SW cloud feedback could be decomposed by category of Estimated Inversion Strength (EIS, Bretherton, 2015) that characterizes the coupling between the boundary layer and the free troposphere, because the response of cloud to a SST change is different from one EIS category to another. Comparing a map of EIS (Bretherton, 2015; Leahy et al., 2012) with maps of tropical subsidence low-level opaque clouds and thin clouds (not shown) indicates that thin clouds and opaque clouds are associated to different categories of EIS. We find no correlation (i) between the observed anomaly of low cloud volume thin and the observed anomaly of SW CRE or (ii) between the observed anomaly of low cloud volume opaque and the observed anomaly of SW CRE. This suggests that the variation of the CRE SW is not significantly dominated by the variation of one of these two populations.

Finally, we also found (not shown) that the interannual evolution of the anomaly in low cloud volume thin is anticorrelated with the interannual evolution of the anomaly in low cloud volume opaque. This highlights the constant transitions between those two types of clouds at an interannual time scale, and inclined us to consider all low clouds together instead of separating thin and opaque clouds in this region. We unsurprisingly found some correlation (0.71; Table S1) between low cloud volume (thin and opaque clouds) and the CRE SW, as the subsidence tropical SW TOA CRE is influenced by changes in the low cloud volume.

\subsubsection{The SW CRE is Driven by the Low Cloud Volume in the Observations and Models}

Figure $2 \mathrm{~b}$ shows time series of the observed low cloud volume and the observed SW CRE in anomalies. The low cloud volume influences the SW CRE: when the low cloud volume increases, the boundary layer contains more condensed water and the SW CRE cooling effect increases. During the last 10 years, neither the observed low cloud volume nor the observed SW CRE exhibit significant trends. In the current climate, the model SW CRE varies with the modeled low cloud volume (Table S1), consistently with observations: typically $16 \%$ change in SW CRE $\left(+6.1 \mathrm{~W} / \mathrm{m}^{2}\right)$ for a $1 \%$ absolute change in the low cloud volume, confirming that the low cloud volume influences the CRE SW consistently in observations and models.

\subsubsection{Sensitivity of the Low Cloud Volume to the SST}

In the observations over the last decade, the low cloud volume decreases when the SST increases (Table S1). In the current climate simulations, the sensitivity of the cloud volume to an SST increase depends on the model. In HadGEM2, the sign of the sensitivity with respect to SST ( -2.23 absolute $\%$ change per $\mathrm{K}$ ) is consistent with observations in present-day climate $(-0.42 \%$ per $\mathrm{K})$, and also as the climate warms $(-0.35 \%$ per $\mathrm{K})$ : the cloud volume in the boundary layer subsidence in the tropics decreases, consistently with mechanisms described in the recent literature (e.g., Klein \& Hall, 2015). On the other hand, for the second model, the correlation between the low cloud volume and the SST is insignificant in the current climate, and then as the global climate warms (Table S1; warmer climate), CanAM4 model predicts a small increase of the low cloud volume associated to a decrease of SW CRE. This suggests that the clouds in this model do not respond to SST increase following the same mechanism as in the previous model.

The different behaviors of these two models underline (1) the uncertainty on the sensitivity of the boundary clouds to the SST in this region in the modeled current climate and (2) the likely related uncertainty on the modeled cloud feedback estimates from different climate models. Monitoring changes in low cloud volume may provide useful constraining information by pointing out which model, and which cloud feedback mechanism, are closer to reality. 


\subsection{Cloud SW Feedback in the Southern Ocean}

In a warming climate, while the global mean cloud-climate feedback in response to increase greenhouse gases is likely positive (Boucher et al., 2013), most climate models feature negative cloud feedback in the Southern Ocean (Zelinka et al., 2012). These negative cloud feedback are dominated by the SW term, and they are a consequence of optical depth increases, with a contribution from clouds changing in phase from ice to liquid (Kay et al., 2014; Tsushima et al., 2006) and a contribution from poleward jet shifts (Bodas-Salcedo et al., 2014; Ceppi \& Hartmann, 2015; Grise \& Polvani, 2014; Kay et al., 2014). Gordon and Klein (2014) and Klein and Hall (2015) identified the sensitivity of the low-level cloud optical depth to the SST in the extratropics as the most promising emergent constraint on cloud feedback.

The Southern Ocean $\left(35^{\circ} \mathrm{S}-65^{\circ} \mathrm{S}\right)$ is the region with the largest SW negative feedback. The two models used in the current study produce negative SW feedback $\left(-0.6 \mathrm{~W} \cdot \mathrm{m}^{-2} \cdot \mathrm{K}^{-1}\right.$; Table S1) representative of the multimodel mean in the region.

\subsubsection{Choice of the Observable Cloud Diagnostic: The Opaque Cloud Volume}

The Southern Ocean is overcast almost all the time. The storm track clouds found there are optically thick. In such conditions the lidar often cannot probe the atmosphere entirely from the TOA down to the surface: usually it reaches the top of the boundary layer, 1 to $2 \mathrm{~km}$ above sea level (Guzman et al., 2017). Most of the liquid clouds and part of the ice clouds contained in this region are opaque, which the lidar laser light cannot penetrate. Due to the ubiquity of opaque clouds in that region, and the fact that they are responsible for a large SW CRE, we retain the opaque cloud volume diagnostic in the Southern Ocean.

\subsubsection{Link Between the SW CRE and the Opaque Cloud Volume}

Figure $2 c$ shows the observed evolution of SW CRE anomalies and opaque cloud volume during the last decade over the Southern Ocean. The SW CRE remains stable and large: $66.5 \pm 0.5 \mathrm{~W} / \mathrm{m}^{2}$. Such small variations make it hard to evaluate its correlation with any other variable. We find none with the opaque cloud volume, either in observations from the last decade or in climate model simulations. Nevertheless, Guzman et al. (2017) showed that at global scale and in zonal mean, the SW CRE is correlated to the opaque clouds observed by CALIPSO.

When the climate is significantly warmed up (AMIP+4K compared to AMIP), both models predict the opaque cloud volume increases $(+0.7 \%$ absolute opaque cloud volume/K) together with the SW CRE $\left(-0.6 \mathrm{~W} \cdot \mathrm{m}^{-2} \cdot \mathrm{K}^{-1}\right)$ producing a negative SW feedback. In the model world, the opaque cloud volume and the SW CRE are correlated. This cannot be verified in the real world because the SW CRE and the opaque cloud volume do not change enough.

In current climate conditions, CanAM4 simulates a SW CRE mean state similar to the observed mean state, whereas its opaque cloud volume mean state is significantly too large (15\%) compared to observations (3\%), meaning that the modeled mean clouds in this region are unrealistic. HadGEM2-A simulates a SW CRE mean state biased by $10 \mathrm{~W} / \mathrm{m}^{2}$ compared to observations, and like CanAM4 significantly overestimates the opaque cloud volume (15\%). This overestimate of opaque clouds in the Southern Ocean is shared by many models (e.g., Bodas-Salcedo et al., 2014; Guzman et al., 2017; Kay et al., 2016).

\subsubsection{Sensitivity of the Opaque Cloud Volume to the SST}

In the current observational record, the opaque cloud volume varies with the mean SST (Table S1): a warmer ocean produces a larger volume of opaque clouds. Consistently with the observations, in the current climate, the models simulate an increase in opaque cloud volume when the SST increases, but the correlation is much less significant in the models ( 0.3 and 0.5$)$ than in the observations $(>0.8$; details of the computation are given in the supporting information). Moreover, the sensitivity of the opaque cloud volume to the SST in current climate is five times larger in the observations ( $+1 \%$ absolute volume per $\mathrm{K}$ ) than in the models $(+0.2 \%$ absolute volume per K). This might be because in the models the correlation opaque cloud volume and the SST are poor compared to in observations, or because the model mean state is strongly biased toward too large opaque cloud volume that may be less sensitive to SST changes than clouds having a lower opaque cloud volume.

In warmer climate conditions, both models predict an increase in opaque cloud volume in the Southern Ocean, typically $+0.7 \%$ for a $+1 \mathrm{~K}$ global temperature increase (Table S1). This increase is consistent with a negative SW feedback, but since we cannot verify the correlation between the opaque cloud volume and the SW CRE in current climate (which might be or might not be there), the conclusion of this study in the Southern Ocean is weaker. 


\section{Method to Estimate When a Forced Cloud Change Due to Climate Warming Would be Detectable}

Having selected the feedback, the regions, and the cloud diagnostics, this section describes how we determine when a spaceborne lidar record would be able to detect a cloud change due to climate warming. Throughout this description, we apply the method to the opaque cloud altitude (section 3.1.1) in tropical ascent conditions as an example.

\subsection{Building Long-Term Synthetic Time Series}

First, we characterize the observed time series over the last decade following the approach outlined in Weatherhead et al. (1998), referred to hereafter as W98. We use almost 10 years of observations, for comparison Loeb, Wielicki, Wong, et al. (2009) used 5 years. We remove seasonal variations from the diagnostic monthly time series by subtracting from each monthly value the average of all values associated with the same month. From this deseasonalized time series, we remove the linear trend. We suppose that the remaining monthly fluctuations (or "noise") can be modeled as an $\mathrm{AR}(1)$ process, that is, that the noise at month t $N_{t}$ can be derived from the noise from the previous month by $N_{t}=\Phi N_{t-1}+\varepsilon_{t}$, with $\Phi$ the lag-1 autocorrelation between time series lagged by one month, and $\varepsilon_{t}$ the random variables with mean zero and common variance $\sigma_{\varepsilon}^{2}$. As in W98, we obtain this last value from $\sigma_{\varepsilon}^{2}=\left(1-\Phi^{2}\right) \sigma_{N}^{2}$, with $\sigma_{N}^{2}$ as the variance of the noise. We find that for the opaque cloud altitude diagnostic, the deseasonalized and detrended time series can be described by $\Phi=0.04, \sigma_{N}=0.2366 \mathrm{~m}$ and $\sigma_{\varepsilon}=0.2367 \mathrm{~m}$. The autocorrelation $\Phi$ is quite low; thus, the noise is almost normally distributed. This is not the case for all diagnostics. The $A R(1)$ process has been tested and found to be a good one for typical weather and climate observations (Phojanamongkolkij et al., 2014). The $A R(1)$ process provides the ability to simulate the typical "red noise" spectrum seen in weather/climate data by introducing an autocorrelation time scale. Gaussian white noise would be a much poorer approximation. The Leroy, Anderson, Dykema, et al. (2008) and Leroy, Anderson, and Ohring (2008) method is in theory more general, but Phojanamongkolkij et al. (2014) show that the AR(1)-based Weatherhead et al. (1998) analysis gives similar results to the Leroy, Anderson, Dykema, et al. (2008) and Leroy, Anderson, and Ohring (2008) method.

Second, we calculate 100-year time series. Using $\Phi, \sigma_{N}^{2}$, and $\sigma_{\varepsilon}^{2}$, it is possible to generate time series of monthly fluctuations, of arbitrary length, that respect and reproduce the behavior of the original observed diagnostic time series. We followed the methodology outlined in Phojanamongkolkij et al. (2014) to generate 100-year time series of fluctuations. We can generate any number of such time series and settled on 200 (for comparison, Loeb, Wielicki, Wong, et al., 2009, used 50). For each model, we then impose these fluctuations to the linear trend it predicts. For example, considering the atmosphere predicted by HadGEM2-A in the tropical ascent region, the opaque cloud altitude is $+1.44 \mathrm{~km}$ higher than in current climate (Table S1). Supposing, as Chepfer et al. (2014), a linear transition between the current climate and $+4 \mathrm{~K}$ conditions translates that change to a trend of $\omega_{0}=+14.4 \mathrm{~m} /$ year.

For each model, we obtain 200 long-term synthetic time series for each diagnostic (the blue line in Figure 3a shows one) that respect both the observed natural variability and the GCM-predicted long-term trend $\omega_{0}(+14.4 \mathrm{~m} /$ year for HadGEM2-A; black dashed horizontal line in Figure $3 \mathrm{~b})$. From such time series we can estimate how fast the cloud change due to SST forcing of each diagnostic exceeds natural climate variability.

\subsection{Computing the Trend}

For a particular spaceborne record length $t$ (with $t<100$ years) we can extract a subset of the synthetic diagnostic time series between 2008 and 2008+t. Applying a linear regression on that subset provides a linear trend $\omega_{t}$. Figure 3 a shows that considering $t=5$ years predicts a negative trend (red line), while considering $t=17$ years predicts a positive trend (yellow line). The magnitude and the sign of the retrieved trend can fluctuate significantly depending on the length of the available lidar record, especially in the early years. When the considered record becomes long enough, the retrieved trend eventually stabilizes.

Computing the linear regression $\omega_{t}$, considering all possible record lengths from 0 (2008) to 100 years (2108) leads to Figure $3 \mathrm{~b}$. After oscillating wildly during the first years, $\omega_{t}$ stabilizes as the record gets longer, to finally settle near the $\omega_{0}=+14.4 \mathrm{~m} /$ year predicted by HadGEM2-A (horizontal black dashed 

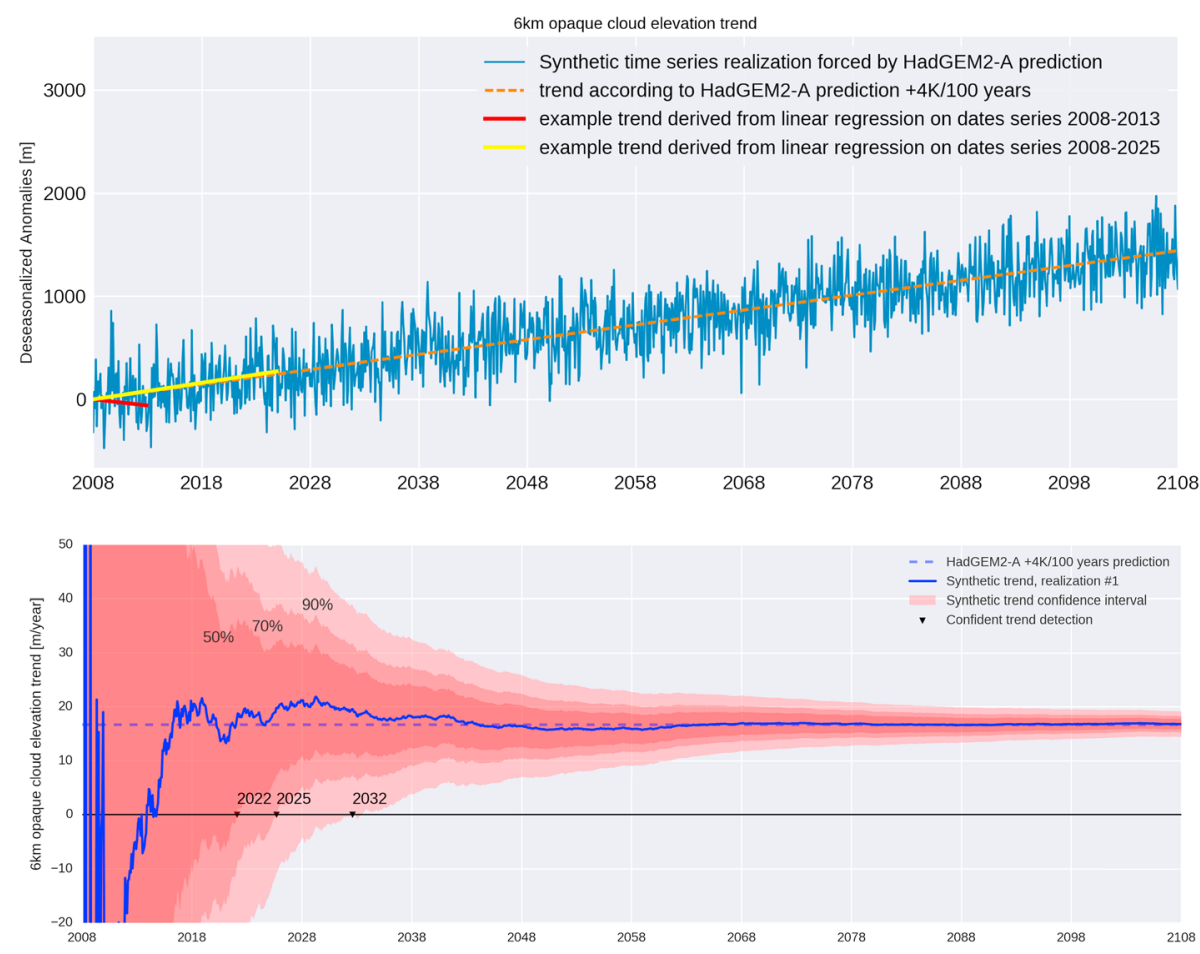

Figure 3. Method used to determine when the forced change goes out of the natural climate variability. (a) Synthetic time series of elevation for opaque clouds in ascent tropics. The synthetic time series forced by HadGEM2-A prediction uses COSP output. (b) Slope of the linear regression as a function of lidar observation record length using one model + COSP/ lidar prediction and different confidence interval (50\%, 70\%, and $90 \%)$. All figures consider a best-case scenario of continuous lidar record with constant performance and sensitivity.

line). In the rest of the study we try to estimate when the trend retrieved from a particular diagnostic comes close to the value predicted by the model, enough that the model trend could be retrieved from analyzing the observations. In the rest of the study we label this event the "convergence time" of the time series. Early convergence time means we will be able to identify the considered cloud trend unambiguously with even a short spaceborne lidar record. Conversely, a convergence time further in the future means that longer spaceborne lidar records will be required to identify unambiguously the associated cloud trend, that is for the climatic signal to exceed natural climate variability. Convergence requires two conditions.

First, as W98, we posit that a real trend is indicated at the $95 \%$ confidence level when $\left|\frac{\omega}{\sigma_{\omega}}\right|>2$, with $\sigma_{\omega}$ as the standard deviation of the trend approximated by $\sigma_{\omega} \sim \sigma_{N} \sqrt{\frac{1+\phi}{1-\phi}} n^{-3} / 2$. In practice, for a time $t$, we compute $\sigma_{N}$ (standard deviation of the noise), $\Phi$ (lag-1 autocorrelation), and $n$ (number of years) using the time series between 0 and $t$. From these we derive $\sigma_{\omega}$ and $\omega_{t}$ and evaluate from the decision rule above if the trend $\omega$ is real. We also impose the trend value $\omega_{t}$ to be close to the predicted value $\omega_{0}$ using the following criteria: $\omega_{0} \in\left[\omega_{t}-2 \sigma_{\omega} \omega_{t}+2 \sigma_{\omega}\right]$

\section{Results}

\subsection{Detectability of the Feedback Signatures in a Lidar Record}

\subsubsection{Detectability of Deep Convective LW Feedback Signature in a Lidar Record}

Figure 4 shows the elevation trend of opaque cloud altitude, for the two models, as a function of the length of the record, considering an ideal time series without mission gaps and without calibration offsets between successive missions for two different models.

Regarding the detectability of the feedback, Figure 5 shows the PDF of what year each of the random time series samples (Figure $4 a$ ) reached that confidence level $(50 \%, 70 \%$, and $90 \%)$. Figures $5 \mathrm{a}$ and $5 \mathrm{~b}$ 

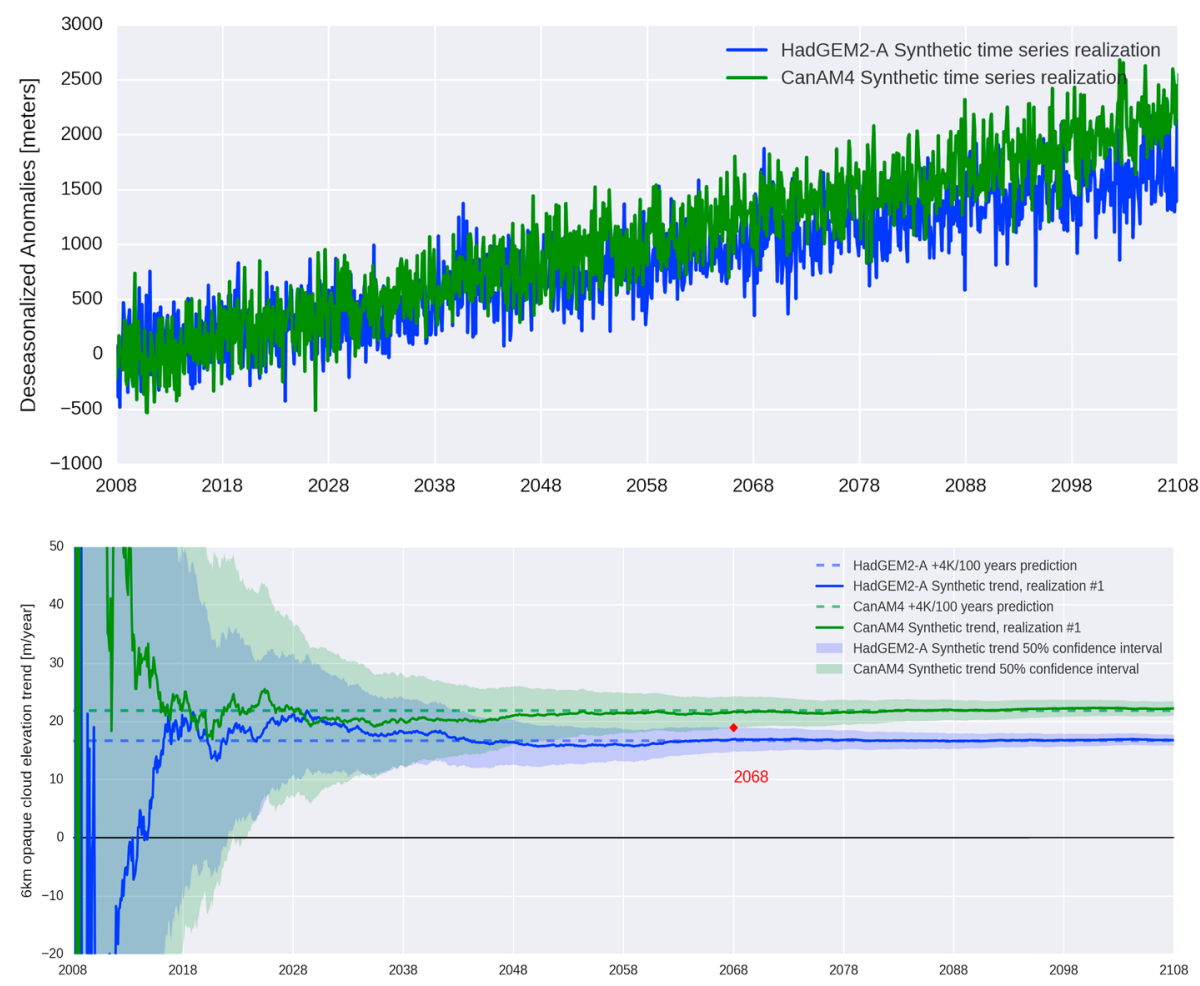

Figure 4. Ascent tropics. (a) Same as Figure 3a but for two models instead of one. (b) Same as Figure 3b but for two models instead of one.

suggest that the two models consistently predict that a 20-year record (2006-2026) is necessary to observe a robust increase in the opaque cloud altitude at $70 \%$ confidence, if we had a continuous observations record since CALIPSO launch. It means that in absence of a third lidar cloud satellite mission after CALIPSO and EarthCARE (i.e., beyond 2023), our confidence on any retrieved trend would remain at most $50 \%$ even in the ideal situation-no gap between CALIPSO and Earth-CARE, both lidars perfectly cross calibrated with the same equatorial crossing time. Adding a third ideal lidar mission overlapping with Earth-CARE would allow completing the record and increase the confidence.

As predictions from the two models are quite similar and pretty consistent for this opaque cloud altitude trend, it would require a long record (typically 50 years at 50\% confidence; Figure $5 \mathrm{c}$ ) to distinguish between the small differences in their predictions. Nevertheless, CanAM4 has much stronger LW feedback than HadGEM2-A (section 4.1 and Table S1), but cloud altitude only increases 30\% faster than HadGEM2-A. This suggests that high CF might play a more discriminating role between models than cloud altitude. But just because these two models agree on the opaque cloud altitude increase, with something as uncertain as cloud physics, we cannot assume that reality will agree with the models. We must measure the height trends from nature, not just models.

\subsubsection{Detectability of Tropical Subsidence SW Feedback in a Lidar Record}

Figure 6a shows deseasonalized time series of low cloud volume that would be observed over the subsidence tropical region by a lidar overflying continuously around the Earth during 100 years, assuming that the global mean Earth temperature warms up by $4 \mathrm{~K}$ in 100 years. HadGEM2 (blue) predicts a decrease in the low cloud volume, associated to a positive SW cloud feedback, whereas CanAM4 (green) predicts a slight increase in time associated to a negative SW cloud feedback. Figure $6 \mathrm{~b}$ shows the trend (in low cloud volume change per year), at 50\% confidence interval, computed from the records shown in Figure $6 \mathrm{a}$, as a function of the length of the record.

Figures $7 \mathrm{a}$ and $7 \mathrm{~b}$ show that a perfect CALIPSO-like record, without interruption or calibration differences between missions, would allow to detect the trend with $70 \%$ confidence in 2028 for one model and in 2037 for the other model. Figure $8 c$ shows that the two model predictions (one leading to a positive 

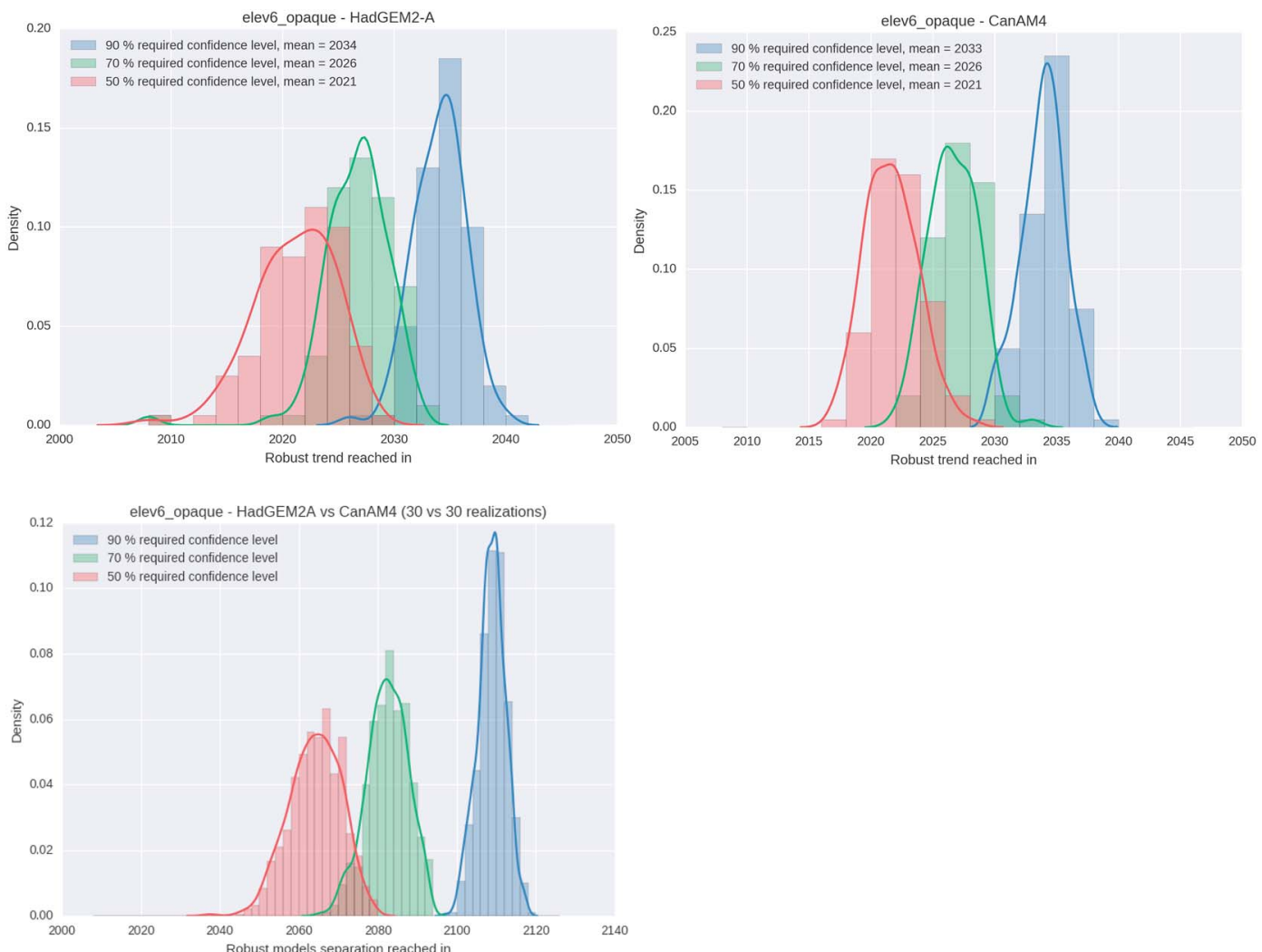

Figure 5. Ascent tropics. PDF of the date at which a robust trend can be reached for a given model. (a) HadGEM2-A model. (b) CanAM4 model. (c) PDF of the date at which the two model predictions robustly separate.

SW cloud feedback and the other to a negative feedback) would be robustly separated with $70 \%$ confidence in 2033, so with a 26-year lidar record.

\subsubsection{Detectability of SW Southern Ocean Feedback Signature in a Lidar Record}

Figure 8a shows the opaque cloud volume record that would be retrieved over the Southern Ocean by an ideal long-term lidar, assuming an increase of the global mean Earth temperature of $+4 \mathrm{~K}$ in 100 years and considering the cloud changes predicted by the two models. It shows that the slopes of the expected trends are quite large compared to the noise of the natural climate variability, suggesting that climate signal should show up rapidly in this region if model predictions were right. In the realization shown in Figure $8 \mathrm{~b}$, the trend (i.e., the change of opaque cloud volume by year) is reported positive typically after 2025 for both models at $50 \%$ confidence.

Figures $9 \mathrm{a}$ and $9 \mathrm{~b}$ show that models consistently predict that the opaque cloud volume change associated to the SW Southern Ocean feedback could be observed with 70\% confidence by 2029 if there was continuous perfect lidar observation record since 2008 launch, and if model predictions were robust.

5.1.4. Comparison of the Convergence Time in the Different Regions: Impact of the Record Length In sections 5.1.1 to 5.1.3, we applied the method to three regions, each with its own cloud diagnostic (Table S1) considering a best-case scenario of uninterrupted lidar record with no performance change. This idealized scenario lets us quantify the time of convergence associated to an interval of confidence. If the record is too short, the change from the long-term trend remains within the range of natural variability, and both cannot be unraveled.

Comparing the three regions indicates that if model predictions are right and the lidar record is perfect, then the climatic signal goes out of the natural variability fastest in the tropical deep convective regions (2026 at $70 \%$ confidence), and later in the Southern Ocean (2029 at 70\% confidence) and the subsidence tropical regions (2028 at $70 \%$ confidence). 

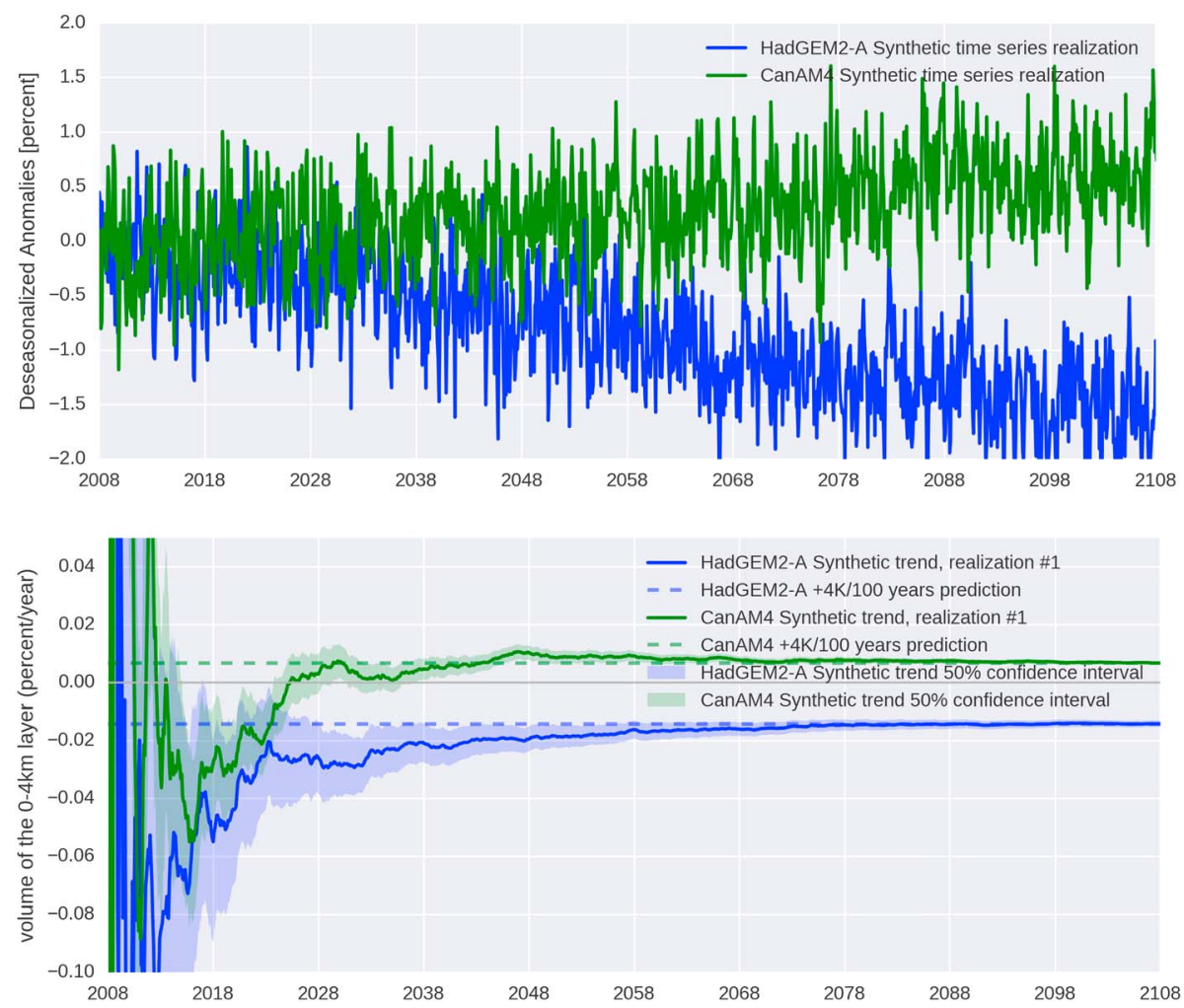

Figure 6. Same as Figure 4 but for subsidence tropics.

\subsubsection{Sensitivity of the Convergence Time to the Speed of the Earth Warming}

The choice of the length of the time series (100 years) is arbitrary, and one could argue that it might not be a realistic choice. The amount of warming that will occur over the next 100 years is uncertain, and it will depend on the socioeconomic pathway and the transient sensitivity of the system.

We analyzed an ensemble of scenarios that span a range of warming: $+4 \mathrm{~K}$ in 50 years and $+4 \mathrm{~K}$ in 125 years. We found that the uncertainty on the time of convergence depends on the speed of the Earth warming: the slower Earth warming (125 years) leads to larger PDFs than the faster Earth warming (50 years). Nevertheless, the mean time of convergence over all the realizations is poorly sensitive on the speed of the Earth warming. For example, the opaque cloud elevation trend of opaque cloud altitude shifts from 2033 for 50 years to 2034 for 125 years, for the $90 \%$ confidence level.

\subsection{Impacts of Mission Scenarios (length, gaps, shifts) on the Ability to Constrain Cloud Feedback}

Real-life constraints, such as mission launch schedules and instrument performance variations, will affect the spaceborne lidar record and convergence time. To study how, we modify the 100-year time series of synthetic height-intensity histograms based on the expected spaceborne lidar mission schedule. We then extract diagnostic time series from these tainted data sets that we compare to the original one.

We segmented the 100-year timeline based on the expected launch dates and lifetimes of ongoing and future lidar missions. As an example, Figure 10a shows this segmentation applied to the trend retrieved from a HadGEM2-A realization of opaque cloud altitude in tropical deep convection conditions. We consider that the following missions will contribute the most to an extended spaceborne lidar record dedicated to the monitoring of changes in the global cloud distribution (Figure 10a):

1. The CALIPSO mission (Winker et al., 2010), launched in 2006, source of the CALIPSO-GOCCP data used to derive diagnostics (section 3) and expected to operate until 2018 at least, is at the time of writing the only cloud lidar in space operating continuously.

2. The Earth-CARE mission (Illingworth et al., 2015), expected to launch in 2020, will operate a 355-nm lidar that will provide cloud detections reconcilable with CALIOP's (Reverdy et al., 2015). 

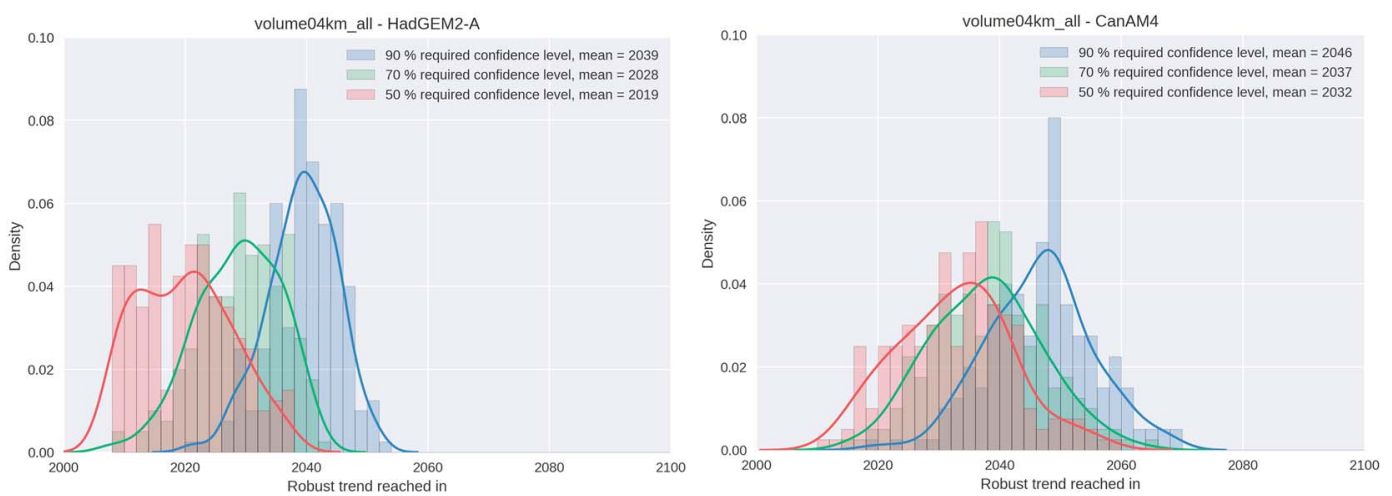

volume04km_all - HadGEM2A vs CanAM4 (30 vs 30 realizations)

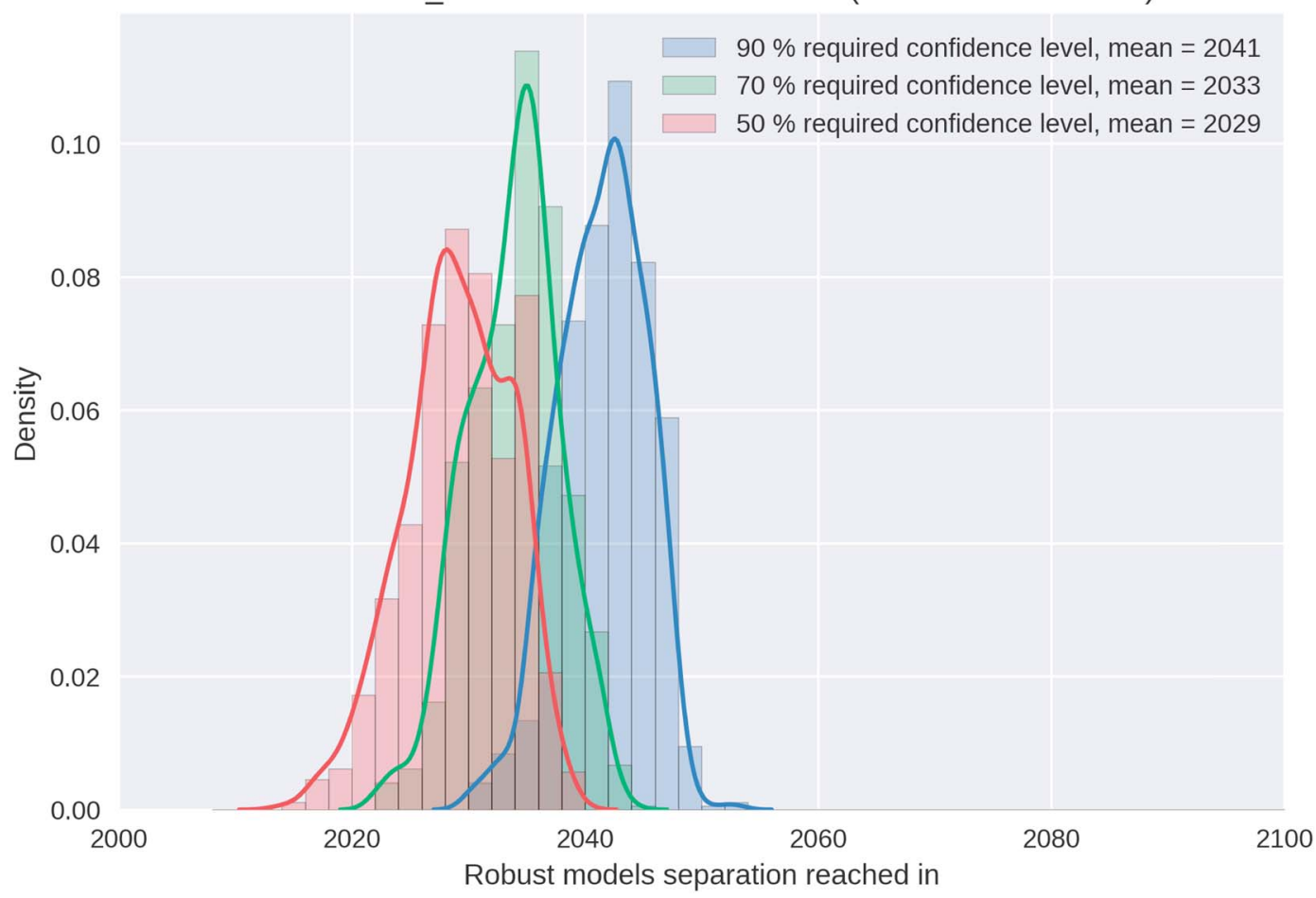

Figure 7. Same as Figure 5 but for subsidence tropics.

3. The MESCAL project is a spaceborne lidar project, currently in preliminary phase definition, to follow-up CALIPSO and Earth-CARE.

4. Another unnamed mission in the far future to reach the spaceborne lidar record length necessary to detect climate-related cloud trends.

We consider the possibility of "blind" periods with no spaceborne lidar measurement, two years between the CALIPSO and Earth-CARE missions (scenario 1) and two years between Earth-CARE and MESCAL missions (scenario 2), which might happen due to schedule priorities. In these scenarios, we remove data from the synthetic height-intensity histograms for the expected blind period, retrieve the appropriate diagnostic for the pruned data set, and apply to it the regression steps described in section 4. In addition, we also consider possible intercalibration errors between successive instruments, which is highly probable, for many reasons: for instance, Earth-CARE carries a high spectral resolution lidar that does not use the same calibration technique as the CALIPSO non-high spectral resolution lidar (see Reverdy et al., 2015, for a list of instrumental and orbital differences between missions that could impact the intercalibration of their instrument). These might result in either positive or negative offsets in cloud altitude retrievals between successive instruments. We explore how both factors affect the convergence time of a given diagnostic time series. 

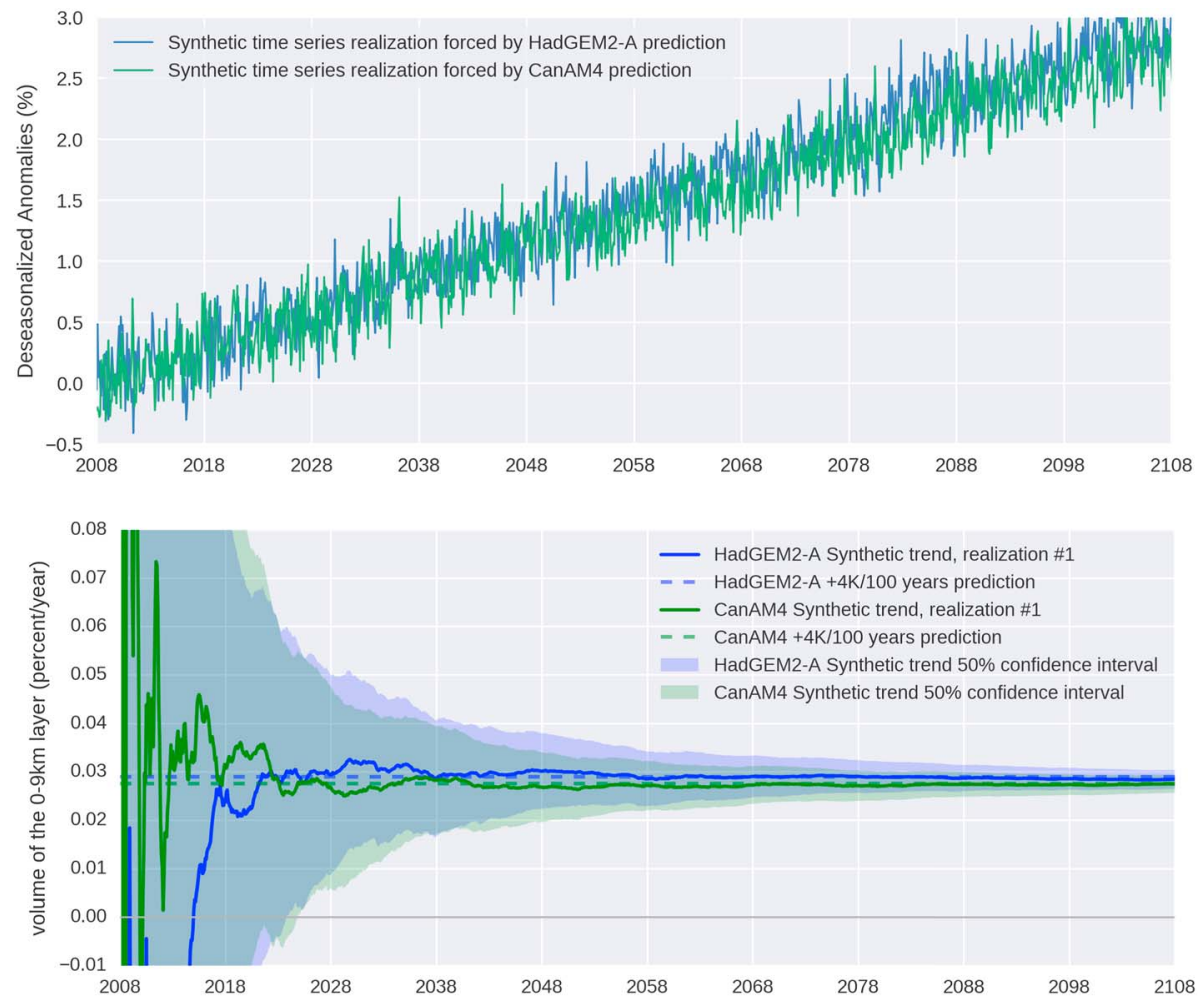

Figure 8. Same as Figure 4 but for Southern Ocean.

We first examined the impact of a gap between two successive missions that are perfectly intercalibrated. In the deep convective tropical region, we concluded (not shown) that a two-year gap between two successive missions has no impact on the time of convergence if the two missions are perfectly intercalibrated (not shown). A longer gap (not showed) increases the time of convergence and delay the capability to detect trends.

Figure 10b shows the trend value as a function of the length of the record for the same trend as Figure 10a, but adding $\pm 100 \mathrm{~m}$ shifts between CALIPSO and Earth-CARE and between Earth-CARE and MESCAL (the black vertical lines show mission changes). The detection of a trend date gets later if there is a negative opaque cloud height error, and shorter if there is a positive error. This is because the model expected climate trend is positive, and therefore, the positive height error exaggerates the true trend to a larger than real value and therefore is "detected" earlier. But this is a false detection, due to intercalibration issues, that would disappear once the issues are recognized and fixed. To avoid this situation, one needs to examine not only the trend but also the actual value of the opaque cloud altitude.
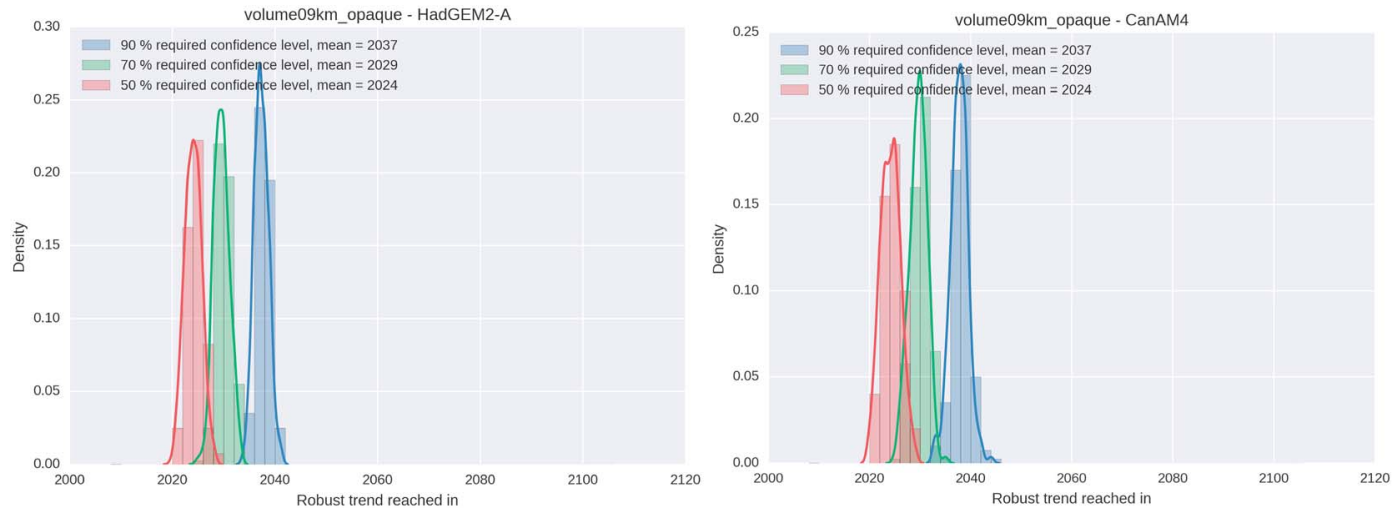

Figure 9. Same as Figure 5 but for Southern Ocean. 

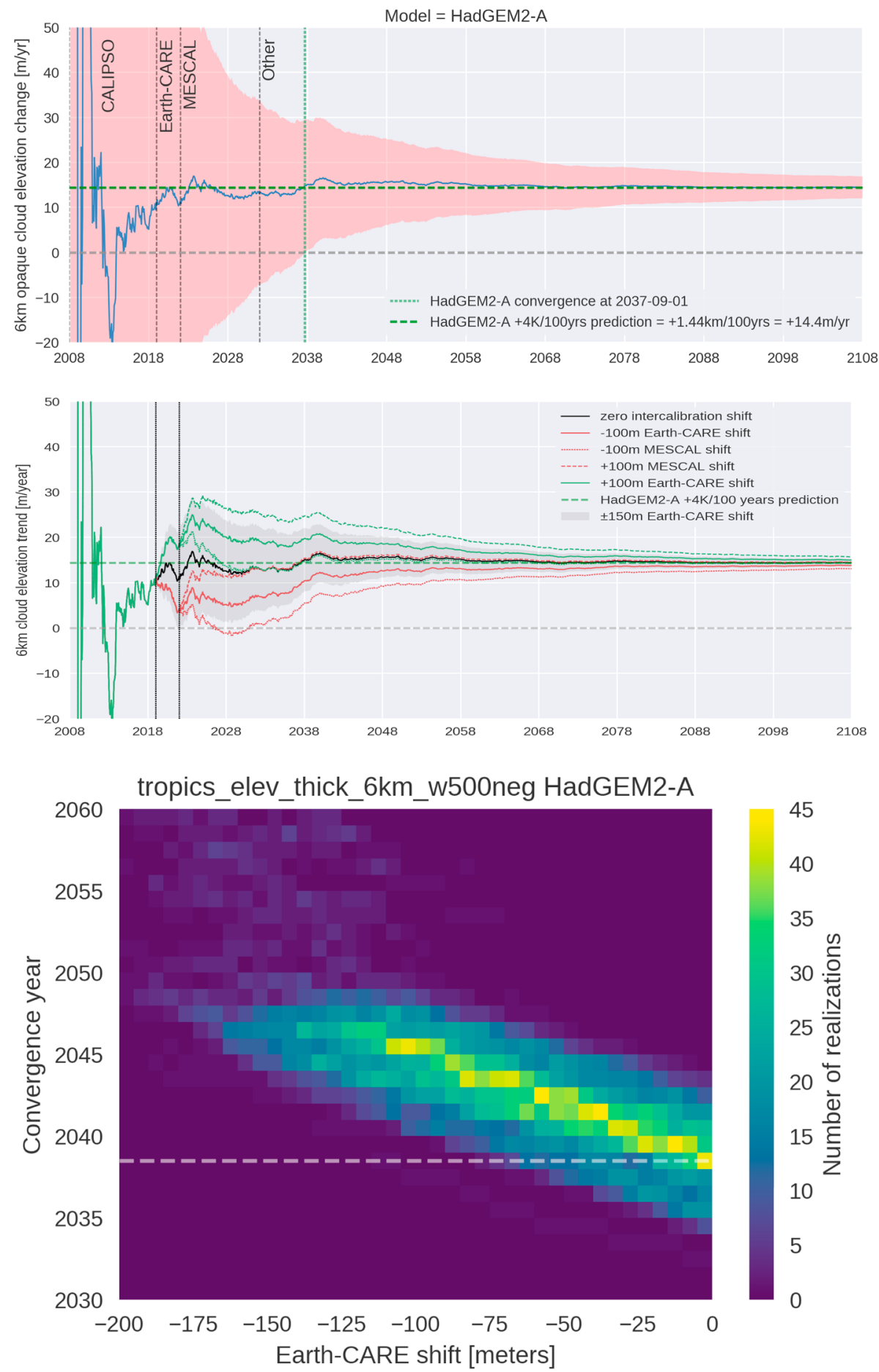

Figure 10. Impact of intercalibration shifts between successive missions on the convergence date for tropical ascent: (a) opaque cloud elevation change as a function of the length of the lidar record. Operation periods of satellite lidar missions, supposed successive, are delimited by black vertical dotted lines, and the horizontal dashed green line is the reference trend from model predictions in $+4 \mathrm{~K}$ conditions. (b) Elevation trend for opaque clouds as a function of observation time. The black line considers a continuous and unbiased lidar record; the dotted lines, respectively, add a +100 and $-100 \mathrm{~m}$ intercalibration shift between Earth-CARE and MESCAL. (c) Time of convergence as a function of Earth-CARE shift with respect to CALIPSO. 
Figure 10c shows the convergence as a function of the amplitude of the shift between Earth-Care and Mescal when there is a negative opaque cloud altitude error. When two successive missions are not perfectly intercalibrated (Figure 10b), then the convergence time is delayed compared to when they are perfectly intercalibrated. The time to detect a trend (convergence time) is delayed by several years, depending on the amplitude of the shift.

\section{Conclusion}

This study explores the potential for a multidecade active sensor record to observe cloud feedback signatures and to constrain cloud feedback spread predicted by climate models.

We focused on three different regions where cloud feedback mechanisms have been proposed in modelbased literature, but have not yet been robustly verified in the observations: the LW positive cloud feedback in deep convective tropics (w500 < 0), the SW positive cloud feedback in the subsidence tropics (w500>0), and the SW negative feedback in the Southern Ocean $\left(35^{\circ} \mathrm{S}-65^{\circ} \mathrm{S}\right)$. In each region, we identified observable cloud diagnostics (opaque cloud altitude, low cloud volume, and opaque cloud volume) derived from Level 1 lidar observations that (i) influence the CRE (SW or LW) and (ii) respond to SST change in both observations and climate simulations in current and future conditions.

We then built synthetic records of these cloud diagnostics as they would be observed by a perfect long-term lidar in space overflying the atmosphere predicted by two climate models during a century. These synthetic records are currently our best guess of the predicted evolution of the Earth's atmosphere through a lidar lens. We forced the short-term variability of these records based on observations during the last decade by CALIPSO, whereas their long-term trend is forced by predictions from climate models in a specific climate warming scenario.

Analyzing these records, we found that if model predictions were right, a perfect 20-year lidar record would be able to constrain with $70 \%$ confidence the positive LW deep convective feedback. The differences in the SW tropical subsidence feedback predicted by the two models could be distinguished at $70 \%$ confidence with a 27-year perfect lidar record. The negative SW Southern Ocean would be constrained with $70 \%$ confidence by a 29-year perfect lidar record. The Southern Ocean results are less robust than the others because the correlation between the cloud diagnostic and the SW CRE has not been robustly demonstrated yet in current climate. We also found that any intercalibration shift between successive lidar-in-space missions would delay the capability to constrain the cloud feedback, and the delay depends on the amplitude of the interca-

Acknowledgments

The authors acknowledge M. Reverdy for doing the first prestudy related to this paper, as well as T. Vaillant de Guélis, R. Guzman, and M. Chakroun for their inputs. The authors acknowledge Steve Klein for discussion and helpful comments on this work. Thanks are due to CNES, to ESA, and to ClimServ/CNRS for contributing to the funding of this work, and to NASA and CNES for providing CALIPSO Level1 data. We acknowledge the World Climate Research Program's Working Group on Coupled Modelling, responsible for CMIP, and we thank the climate modeling groups (HadGEM and (CCMA) for producing and making available their model outputs. For CMIP the U.S. Department of Energy's Program for Climate Model Diagnosis and Intercomparison provides coordinating support and led development of software infrastructure in partnership with the Global Organization for Earth System Science Portals. The climate model outputs used in this study are available through https://esgf.Ilnl.gov. The observations used in this study are available on http://climserv.ipsl.polytechnique.fr/ cfmip-obs/. We acknowledge the anonymous reviewers who strongly helped to improve the manuscript. libration shift. Analyzing the current CALIPSO data set, by comparison, did not reveal any significant trend in any diagnostic in any region.

The numbers given here above are only indicative and should not be overinterpreted, as they rely on climate model simulations from only two models. All models have significant biases in their current climate cloud mean state, those likely impact our results. Moreover, the simulations used in this study are not considering atmosphere-ocean interactions, which would influence the results (Armour, 2016): in particular, estimates of how long it will take for feedback signature to clearly emerge can be currently underestimated due to patterned warming responses. In addition, the hypothesis on the rate of increase in SST (a linear rise to $+4 \mathrm{~K}$ in 100 years) also influences the results. Uncertainties in the results are also due to observations, as, for example, the A-Train and Earth-CARE sampling have a 30-min difference in local time, which may impact the trend detectability. Future CMIP6 simulations (Webb et al., 2017) should provide lidar simulator outputs for more models, fully coupled simulations, improved cloud descriptions, and tools to evaluate and to improve the model cloud mean state. Hence, the numbers given above will be refined in a future study using CMIP6 outputs. In particular, these new model data sets could be used in the future to reduce the noise in the relationships between lidar chosen metrics and the CRE by using better metrics, in particular over Southern Ocean (but not only).

The virtual lidar record exercise done in this paper provides a strong motivation for producing more refined simulations and for further exploring the potential of a multidecade lidar-in-space record to constrain cloud feedback.

\section{References}

Armour, K. C. (2016). Projection and prediction: Climate sensitivity on the rise. Nature Climate Change, 6, 896-897. https://doi.org/10.1038/ nclimate 3079

Bodas-Salcedo, A., Web, M. J., Bony, S., Chepfer, H., Dufresne, J.-L., Klein, S. A., et al. (2011). COSP: Satellite simulation software for model assessment. Bulletin of the American Meteorological Society, 92, 1023-1043. https://doi.org/10.1175/2011BAMS2856.1 
Bodas-Salcedo, A., Williams, K. D., Ringer, M. A., Beau, I., Cole, J. N. S., Dufresne, J.-L., et al. (2014). Origins of solar radiation biases over the Southern Ocean in CFMIP2 models. Journal of Climate, 27, 41-56. https://doi.org/10.1175/JCLI-D-13-00169.1

Bony, S., Dufresne, J.-L., Le Treut, H., Morcrette, J.-J., \& Senior, C. (2004). On dynamic and thermodynamic components of cloud changes. Climate Dynamics, 22, 71-86.

Bony, S., Webb, M., Stevens, B., Bretherton, C., Klein, S., \& Tselioudis, G. (2009). The cloud feedback model intercomparison project: Summary of activities and recommendations for advancing assessments of cloud climate feedbacks. Retrieved from http://cfmip.metoffice.com/ CFMIP2_experiments_March20th2009.pdf

Boucher, O., Randall, D., Artaxo, P., Bretherton, C., Feingold, G., Forster, P., et al. (2013). Clouds and aerosols. In T. F. Stocker, et al. (Eds.), Climate Change 2013: The Physical Science Basis. Contribution of Working Group I to the Fifth Assessment Report of the Intergovernmental Panel on Climate Change (pp. 571-657). Cambridge University Press. https://doi.org/10.1017/CBO9781107415324.016

Bretherton, C. S. (2015). Insights into low-latitude cloud feedbacks from high-resolution models. Philosophical Transactions of the Royal Society A, 373. https://doi.org/10.1098/rsta.2014.0415

Ceppi, P., Brient, F., Zelinka, M. D., \& Hartmann, D. L. (2017). Cloud feedback mechanisms and their representation in global climate models. WIREs Climate Change, 2017, e465. https://doi.org/10.1002/wcc.465

Ceppi, P., \& Hartmann, D. L. (2015). Connections between clouds, radiation, and midlatitude dynamic: A review. Current Climate Change Reports. https://doi.org/10.1007/s40641-015-0010-x

Cesana, G., \& Chepfer, H. (2012). How well do climate models simulate cloud vertical structure? A comparison between CALIPSO-GOCCP satellite observations and CMIP5 models. Geophysical Research Letters, 39, L20803. https://doi.org/10.1029/2012GL053153

Cesana, G., \& Chepfer, H. (2013). Evaluation of the cloud thermodynamic phase in a climate model using CALIPSO-GOCCP. Journal of Geophysical Research: Atmospheres, 118, 7922-7937. https://doi.org/10.1002/jgrd.50376

Chakroun, M., Bastin, S., Chiriaco, M., \& Chepfer, H. (2016). Characterization of vertical cloud variability over Europe using spatial lidar observations and regional simulation. Climate Dynamics. https://doi.org/10.1007/s00382-016-3037-3

Chepfer, H., Chiriaco, M., Vautard, R., \& Spinhirne, J. (2007). Evaluation of the ability of MM5 meso-scale model to reproduce optically thin clouds over Europe in fall using ICE/SAT lidar space-born observations. Monthly Weather Review, 135, 2737-2753.

Chepfer, H., Bony, S., Winker, D., Cesana, G., Dufresne, J.-L., Minnis, P., et al. (2010). The GCM-Oriented CALIPSO Cloud Product (CALIPSOGOCCP). Journal of Geophysical Research, 115, D00H16. https://doi.org/10.1029/2009JD012251

Chepfer, H., Bony, S., Winker, D., Chiriaco, M., Dufresne, J.-L., \& Seze, G. (2008). Use of CALIPSO lidar observations to evaluate the cloudiness simulated by a climate model. Geophysical Research Letters, 35, 15704. https://doi.org/10.1029/2008GL034207

Chepfer, H., Cesana, G., Winker, D., Getzewich, B., Vaughan, M., \& Liu, Z. (2013). Comparison of two different cloud climatologies derived from CALIOP-Attenuated Backscattered Measurements (Level 1): The CALIPSO-ST and the CALIPSO-GOCCP. Journal of Atmospheric and Oceanic Technology, 30(4), 725-744. https://doi.org/10.1175/JTECH-D-12-00057.1

Chepfer, H., Noel, V., Winker, D., \& Chiriaco, M. (2014). Where and when will we observe cloud changes due to climate warming? Geophysical Research Letters, 41, 8387-8395. https://doi.org/10.1002/2014GL061792

Chiriaco, M., Vautard, R., Chepfer, H., Haeffelin, M., Dudhia, J., Wanherdrick, Y., et al. (2006). The ability of MM5 to simulate ice clouds: Systematic comparison between simulated and measured fluxes and lidar/radar profiles at the SIRTA Atmospheric Observatory. Monthly Weather Review, 134, 897. https://doi.org/10.1175/MWR3102.1

Colman, R. (2003). A comparison of climate feedbacks in general circulation models. Climate Dynamics, 20(7), 865-873. https://doi.org/ 10.1007/s00382-003-0310-z

Dee, D. P., Uppala, S. M., Simmons, A. J., Berrisford, P., Poli, P., Kobayashi, S., et al. (2011). The ERA-Interim reanalysis: Configuration and performance of the data assimilation system. Quarterly Journal of the Royal Meteorological Society, 137(656), 553-597.

Gordon, N. D., \& Klein, S. A. (2014). Low-cloud optical depth feedback in climate models. Journal of Geophysical Research: Atmospheres, 119, 6052-6065. https://doi.org/10.1002/2013JD021052

Grise, K. M., \& Polvani, L. M. (2014). Southern hemisphere cloud-dynamics biases in CMIP5 models and their implications for climate projections. Journal of Climate, 27, 6074-6092.

Guzman, R., Chepfer, H., Noel, V., Vaillant de Guélis, T., Kay, J. E., Raberanto, P., et al. (2017). Atmosphere opacity observed by CALIPSO. Journa of Geophysical Research: Atmospheres, 122, 1066-1085. https://doi.org/10.1002/2016JD025946

Hansen, J. E., Lacis, A., Rind, D., Russel, G., Stone, P., Fung, I., et al. (1984). Climate sensitivity: Analysis of feedback mechanisms. In J. E. Hansen, et al. (Eds.), Climate Processes and Climate Sensitivitity, Geophys. Monogr. Ser., 29, M. Ewing (Vol. 5, pp. 130-163). Washington, DC: American Geophysical Union.

Hartmann, D. L., \& Larson, K. (2002). An important constraint on tropical cloud-climate feedback. Geophysical Research Letters, 29(20), 1951. https://doi.org/10.1029/2002GL015835

Illingworth, A. J., et al. (2015). The Earth-CARE satellite: The next step forward in global measurements of clouds, aerosols, precipitation, and radiation. Bulletin of the American Meteorological Society, 96(8), 1311-1332. https://doi.org/10.1175/BAMS-D-12-00227.1

Kay, J. E., Bourdages, L., Chepfer, H., Miller, N., Morrison, A., Yettella, V., \& Eaton, B. (2016). Evaluating and improving cloud phase in the Community Atmosphere Model version 5 using spaceborne lidar observations. Journal of Geophysical Research: Atmospheres, 121 4162-4176. https://doi.org/10.1002/2015JD024699

Kay, J. E., Meideiros, B., Hwang, Y.-T., Gettlemen, A., Perket, J., \& Flanner, M. G. (2014). Processes controlling Southern Ocean shortwave climate feedbacks in CESM. Geophysical Research Letters, 41, 616-622. https://doi.org/10.1002/2013GL058315

Klein, S. A., \& Hall, A. (2015). Emergent constraints for cloud feedbacks. Current Climate Change Reports, 1(4), 276-287. https://doi.org/ $10.1007 / \mathrm{s} 40641-015-0027-1$

Klein, S. A., Zhang, Y., Zelinka, M. D., Pincus, R., Boyle, J., Gleckler, P. J., et al. (2013). Are climate model simulations of clouds improving? An evaluation using the ISCCP simulator. Journal of Geophysical Research: Atmospheres, 118, 1329-1342. https://doi.org/10.1002/jgrd.50141

Konsta, D., Chepfer, H., \& Dufresne, J.-L. (2012). A process oriented characterization of tropical oceanic clouds for climate model evaluation based on a statistical analysis of daytime A-Train observations. Climate Dynamics, 39(9-10), 2091-2108. https://doi.org/10.1007/s00382012-1533-7

Kuang, Z., \& Hartmann, D. L. (2007). Testing the FAT hypothesis in a cloud-resolving model. Journal of Climate, 20, $2051-2057$.

Leahy, L. V., Wood, R., Charlson, R. J., Hostetler, C. A., Rogers, R. R., Vaughan, M. A., \& Winker, D. M. (2012). On the nature and extent of optically thin marine low clouds. Journal of Geophysical Research, 117, D22201. https://doi.org/10.1029/2012JD017929

Leroy, S., Anderson, J., Dykema, J., \& Goody, R. (2008). Testing climate models using thermal infrared spectra. Journal of Climate, 21(9), 1863-1875. https://doi.org/10.1175/2007JCLI2061.1

Leroy, S. S., Anderson, J. G., \& Ohring, G. (2008). Climate signal detection times and constraints on climate benchmark accuracy requirements. Journal of Climate, 21(4), 841-846. https://doi.org/10.1175/2007JCLI1946.1 
Loeb, N. G., Kato, S., Su, W., Wong, T., Rose, F. G., Doelling, D. R., et al. (2013). Advances in understanding top of the atmosphere radiation variability from satellite observations. Surveys in Geophysics. https://doi.org/10.1007/s10712-012-9175-1

Loeb, N. G., Lyman, J. M., Johnson, G. C., Allan, R. P., Doelling, D. R., Wong, T., et al. (2012). Observed changes in top-of-theatmosphere radiation and upper-ocean heating consistent within uncertainty. Nature Geoscience, 5, 110-113. https://doi.org/ 10.1038/NGEO1375

Loeb, N. G., Wielicki, B. A., Doelling, D. R., Smith, G. L., Keyes, D. F., Kato, S., et al. (2009). Toward optimal closure of the Earth's top-ofatmosphere radiation budget. Journal of Climate, 22(3), 748-766. https://doi.org/10.1175/2008JCLI2637.1

Loeb, N. G., Wielicki, B. A., Wong, T., \& Parker, P. A. (2009). Impact of data gaps on satellite broadband radiation records. Journal of Geophysical Research, 114, D11109. https://doi.org/10.1029/2008JD011183

Marchand, R., Ackerman, T., Smyth, M., \& Rossow, W. B. (2010). A review of cloud top height and optical depth histograms from MISR, ISCCP, and MODIS. Journal of Geophysical Research, 115, D16206. https://doi.org/10.1029/2009JD013422

Martin, G. M., Bellouin, N., Collins, W. J., Culverwell, I. D., Halloran, P. R., Hardiman, S. C., et al. (2011). The HadGEM2 family of Met Office Unified Model climate configurations. Geoscientific Model Development, 4(3), 723-757. https://doi.org/10.5194/gmd-4-723-2011

Marvel, K., Zelinka, M., Klein, S. A., Bonfils, C., Caldwell, P., Doutriaux, C., et al. (2015). External influences on modeled and observed cloud trends. Journal of Climate, 28(12), 4820-4840. https://doi.org/10.1175/JCLI-D-14-00734.1

Nam, C. C. W., \& Quaas, J. (2012). Evaluation of clouds and precipitation in the ECHAM5 General Circulation Model using CALIPSO and CloudSat satellite data. Journal of Climate, 25(14), 4975-4992. https://doi.org/10.1175/JCLI-D-11-00347.1

Noel, V., \& Chepfer, H. (2010). A global view of horizontally oriented crystals in ice clouds from Cloud-Aerosol Lidar and Infrared Pathfinder Satellite Observation (CALIPSO). Journal of Geophysical Research, 115, D00H23. https://doi.org/10.1029/2009JD012365

Norris, J. R., Allen, R. J., Evan, A. T., Zelinka, M. D., O’Dell, C. W., \& Klein, S. A. (2016). Evidence for climate change in the satellite cloud record Nature, 536(7614), 72-75.

Norris, J. R., \& Slingo, A. (2009). Trends in observed cloudiness and Earth's radiation budget: What do we not know and what do we need to know? In J. Heintzenberg \& R. J. Charlson (Eds.), Clouds in the Perturbed Climate System (pp. 17-36). Cambridge, MA: MIT Press.

Phojanamongkolkij, N., Kato, S., Wielicki, B. A., Taylor, P. C., \& Mlynczak, M. G. (2014). A comparison of climate signal trend detection uncertainty analysis methods. Journal of Climate, 27(9), 3363-3376. https://doi.org/10.1175/JCLI-D-13-00400.1

Qu, X., Hall, A., Klein, S. A., \& Caldwell, P. M. (2014). On the spread of changes in marine low cloud cover in climate model simulations of the 21st century. Climate Dynamics, 42, 2603. https://doi.org/10.1007/s00382-013-1945-z

Qu, X., Hall, A., Klein, S. A., \& Caldwell, P. M. (2015). The strength of the tropical inversion and its response to climate change in 18 CMIP5 models. Climate Dynamics, 45, 375. https://doi.org/10.1007/s00382-014-2441-9

Reverdy, M., Chepfer, H., Donovan, D., Noel, V., Cesana, G., Hoareau, C., et al. (2015). An EarthCARE/ATLID simulator to evaluate cloud description in climate models. Journal of Geophysical Research: Atmospheres, 120, 11,090-11,113. https://doi.org/10.1002/2015JD023919

Ringer, M. A., McAvaney, B. J., Andronova, N., Buja, L. E., Esch, M., Ingram, W. J., et al. (2006). Global mean cloud feedbacks in idealized climate change experiments. Geophysical Research Letters, 33, L07718. https://doi.org/10.1029/2005GL025370

Soden, B. J., \& Held, I. M. (2006). An assessment of climate feedbacks in coupled ocean atmosphere models. Journal of Climate, 19(14), 3354. https://doi.org/10.1175/JCLI3799.1

Soden, B. J., \& Vecchi, G. A. (2011). The vertical distribution of cloud feedback in coupled ocean-atmosphere models. Geophysical Research Letters, 38, L12704. https://doi.org/10.1029/2011GL047632

Stephens, G. L., Vane, D. G., Boain, R. J., Mace, G. G., Sassen, K., Wang, Z., et al. (2002). The Cloudsat mission and the A-Train. Bulletin of the American Meteorological Society, 83(1), 1771-1790. https://doi.org/10.1175/BAMS-83-12-1771

Stubenrauch, C. J., Rossow, W. B., Kinnem, S., Kinne, S., Ackerman, S., Ackerman, S., et al. (2013). Assessment of global cloud datasets from satellites: Project and database initiated by the GEWEX radiation panel. Bulletin of the American Meteorological Society, 94(7), 1031-1049. https://doi.org/10.1175/BAMS-D-12-00117.1

Su, H., \& Jiang, J. H. (2013). Tropical clouds and circulation changes during the 2006/07 and 2009/10 El Niños. Journal of Climate, 26, 399-413. https://doi.org/10.1175/JCLI-D-12-00152.1

Taylor, K. E., Stouffer, R. J., \& Meehl, G. A. (2012). An overview of CMIP5 and the experiment design. Bulletin of the American Meteorological Society, 93, 485-498. https://doi.org/10.1175/BAMS-D-11-00094.1

Tsushima, Y., Emori, S., Ogura, T., Kimoto, M., Webb, M. J., Williams, K. D., et al. (2006). Importance of the mixed-phase cloud distribution in the control climate for assessing the response of clouds to carbon dioxide increase: Amulti-model study. Climate Dynamics, 27, 113-126.

Vaillant de Guélis, T., Chepfer, H., Noel, V., Guzman, R., Dubuisson, P., Winker, D. M., \& Kato, S. (2017). Link between the outgoing longwave radiation and the altitude where the space-borne lidar beam is fully attenuated. Atmospheric Measurement Techniques. https://doi.org/ 10.5194/amt-2017-115

Vaillant de Guélis, T., Chepfer, H., Noel, V., Guzman, R., Winker, D., \& Plougonven, R. (2017). Using space lidar observations to decompose longwave cloud radiative effect variations over the last decade. Geophysical Research Letters, 44, 11,994-12,003. https://doi.org/10.1002/ 2017GL074628

Vial, J., Dufresne, J. L., \& Bony, S. (2013). On the interpretation of inter-model spread in CMIP5 climate sensitivity estimates. Climate Dynamics, 41(11-12), 3339-3362.

von Salzen, K., Scinocca, J. F., McFarlane, N. A., Li, J., Cole, J. N. S., Plummer, D., et al. (2013). The Canadian fourth generation atmos- pheric global climate model (CanAM4). Part I: Representation of physical processes. Atmosphere-Ocean, 51, $104-125$.

Weatherhead, E. C., Reinsel, G. C., Tiao, G. C., Meng, X.-L., Choi, D., Cheang, W.-K., et al. (1998). Factors affecting the detection of trends: Statistical considerations and applications to environmental data. Journal of Geophysical Research, 103, 17,149-17,161. https://doi.org/ 10.1029/98JD00995

Webb, M., Andrews, T., Bodas-Salcedo, A., Bony, S., Bretherton, C. S., Chadwick, R., et al. (2017). The Cloud Feedback Model Intercomparison Project (CFMIP) contribution to CMIP6. Geoscientific Model Development. https://doi.org/10.5194/gmd-10-359-2017

Webb, M. J., Senior, C. A., Sexton, D. M. H., Ingram, W. J., Williams, K. D., Ringer, M. A., et al. (2006). On the contribution of local feedback mechanisms to the range of climate sensitivity in two GCM ensembles. Climate Dynamics, 27(1), 17-38. https://doi.org/10.1007/s00382$006-0111-2$

Wetherald, R., \& Manabe, S. (1988). Cloud feedback processes in a general circulation model. Journal of the Atmospheric Sciences, 45, $1397-1415$

Wielicki, B. A., Young, D. F., Mlynczak, M. G., Thome, K. J., Leroy, S., Corliss, J., et al. (2013). Achieving climate change absolute accuracy in orbit. Bulletin of the American Meteorological Society, 94(10), 1519-1539. https://doi.org/10.1175/BAMS-D-12-00149.1

Winker, D., Chepfer, H., Noel, V., \& Cai, X. (2017). Observational constraints on cloud feedbacks: The role of active satellite sensors. Survey in Geophysics. https://doi.org/10.1007/s10712-017-9452-0 
Winker, D. M., Pelon, J., Coakley, J. A. Jr., Ackerman, S. A., Charlson, R. J., Colarco, P. R., et al. (2010). The CALIPSO mission: A global 3D view of aerosols and clouds. Bulletin of the American Meteorological Society, 91(9), 1211-1229. https://doi.org/10.1175/2010BAMS3009.1

Zelinka, M. D., \& Hartmann, D. L. (2010). Why is Longwave Cloud Feedback Positive? Journal of Geophysical Research, 115, D16117. https://doi. org/10.1029/2010JD013817

Zelinka, M. D., Klein, S. A., \& Hartmann, D. L. (2012). Computing and partitioning cloud feedbacks using cloud property histograms. Part II: Attribution to changes in cloud amount, altitude, and optical depth. Journal of Climate, 25, 3736-3754. https://doi.org/10.1175/JCLID-11-00249 